클 Springer

Applied Biochemistry and Biotechnology 
Volume 190, issue 3. March 2020

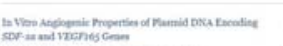

풀

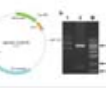

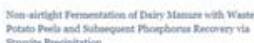

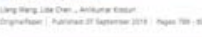

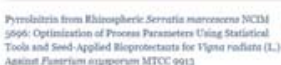

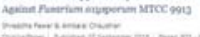

มียับน

For anthors

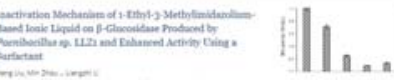

min

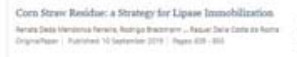

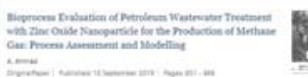

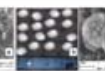

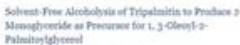

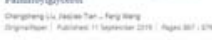

nised

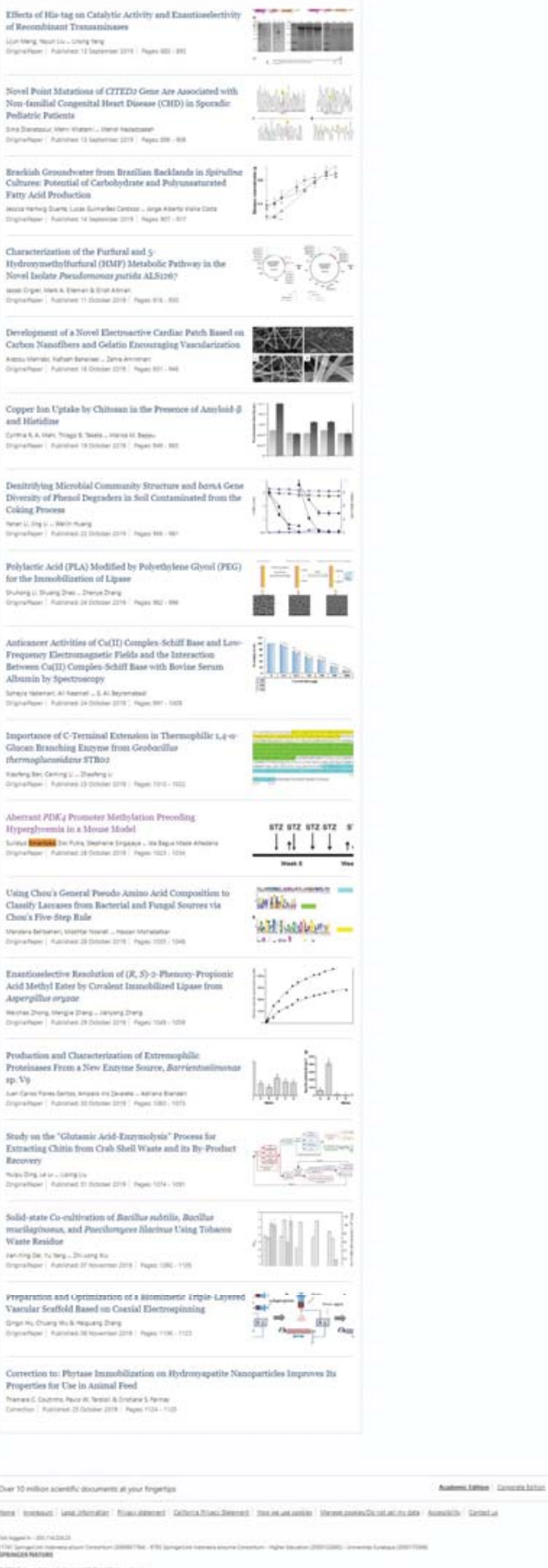


Applied Biochemistry and Biotechnology

Editors

roiros-in-ceats

De. Jonstan Such

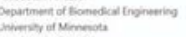

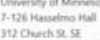

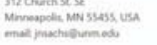

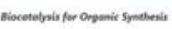

semier tatitar

a. rentions

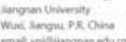

Anittam tititore

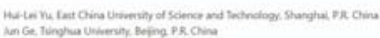

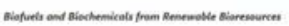

senier tation

pred lis boo

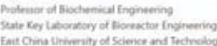

Shangut proins

Awocise tititon

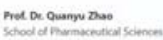

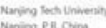

Numing prosions

med De Matato rovimoto

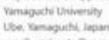

Auintant tditor:

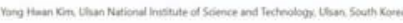

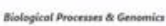

senier tatiter:

De rement in motat

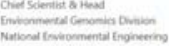

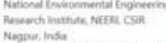

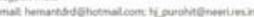

Asaitum tefitore

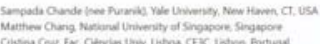

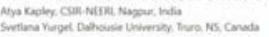

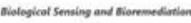

Namociste tatitar

Prod De Benedact obche

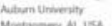

Monsoner, Ne use.

enintam tditars

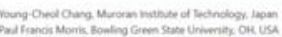

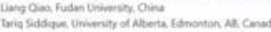

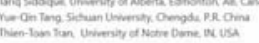

Emivennmed Taricology and Mntaremestiotion

Aesocistat tititor.

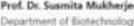

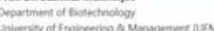

chata idis

Amistrant toditors

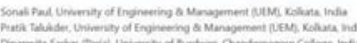

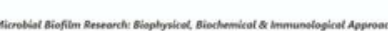

Amociste tation

De. Moupriza Nas

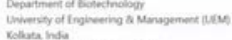

robat insia

Amittam tditors:

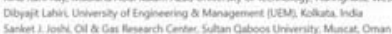

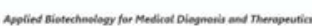

Dr. Jonatur Sectio

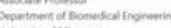

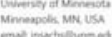

Aaitiont tidion:

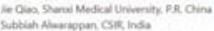

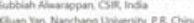

Q) Springe

nowernithis

neway

oncomerement

oterention

For authors

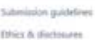

indions

Explose

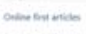

- meitum

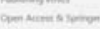

네

nomenom

tomensinger

$n=$

Los

cyons

$\lim _{10}$

nom

Trement

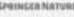


SCOPUS Indexed Journal

Title: Annals of the Romanian Society for Cell Biology

OPEN

\section{Applied Biochemistry and Biotechnology}

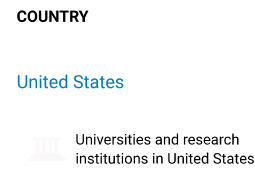

PUBLICATION TYPE

Journals
SUBJECT AREA AND CATEGORY

Biochemistry, Genetics and Molecular Biology Biochemistry

Biotechnology

Molecular Biology

Chemical Engineering

Bioengineering

Environmental Science

Environmental Engineering

Immunology and Microbiology

Applied Microbiology and Biotechnology

Medicine

Medicine (miscellaneous)

\section{SCOPUS Indexed Jourr}

Call For Papers

Title: Annals of the Romanian Socie

Cell Biology

annalsofrscb.ro

OPEN

ISSN

COVERAGE

1981-2020

02732289
H-INDEX

Humana Press

103
INFORMATION

Homepage

How to publish in this journal

jnsachs@unm.edu
Call For Papers Elsevier C

Peer Reviewed Indexed Journal

Collaboration proposals are invited to single platform for worldwide research

turcomat.org
1 of 4 


\title{
Aberrant PDK4 Promoter Methylation Preceding Hyperglycemia in a Mouse Model
}

\author{
Sulistyo Emantoko Dwi Putra ${ }^{1}$ (D) Stephanie Singajaya ${ }^{1} \cdot$ Ferensia Thesman $^{1}$. \\ Dicky Andhika Pranoto ${ }^{1} \cdot$ Ricky Sanjaya $^{1} \cdot$ Yoanes Maria Vianney ${ }^{1}$. \\ Ida Bagus Made Artadana ${ }^{1}$
}

Received: 27 June 2019 / Accepted: 12 September 2019/Published online: 26 October 2019

(C) Springer Science+Business Media, LLC, part of Springer Nature 2019

\begin{abstract}
Diabetic prevalence is at speedy increase globally. Previous studies stated that other than genetics, factors such as environment, lifestyle, and paternal-maternal condition play critical roles in diabetes through DNA methylation in specific areas of the genome. The purpose of this study is to investigate the methylation pattern of the PDK4 promoter in streptozotocin-induced diabetic mice until the 12th week of the observation. The methylation pattern in the blood samples was analyzed periodically, while the pattern in the muscle sample was only analyzed at the end of the experiment using the blood of the sacrificed animals. Three methylated $\mathrm{CpG}$ site $1, \mathrm{CpG}$ site 6 , and $\mathrm{CpG}$ site 7 were analyzed and quantified based on the band density using bisulfite treatment and methylation-specific polymerase chain reaction (PCR). The hyperglycemia period was developed at the 9th week of experiment. However, there was a significant increase of methylation, specifically on $\mathrm{CpG}$ site 6 started from week 6 to week 12. This peculiar methylation on $\mathrm{CpG}$ site 6 of $P D K 4$ promoter in the blood sample before the hyperglycemic period might serve as a potential biomarker for early detection of diabetes in the patients. No significant difference was found between the methylation level of streptozotocin (STZ)-treated mice and of the control group in the muscle sample.
\end{abstract}

Keywords Blood $\cdot$ Epigenetics $\cdot$ Methylation pattern $\cdot P D K 4 \cdot \mathrm{STZ}$-induced diabetic mice

\section{Introduction}

From 151 million in 2000 to 451 million in 2017, global diabetic prevalence has been an increasing trend [1]. Das and Elbein mentioned in their review that parental diabetes is descended on the

Sulistyo Emantoko Dwi Putra

emantoko@staff.ubaya.ac.id

1 Department of Biology, Faculty of Biotechnology, University of Surabaya, Raya Kalirungkut, Surabaya, East Java 60292, Indonesia 
children through gene mutation [2]. Recent studies show that genetics is not the only factor in the emergence of diabetes. Environmental factors such as maternal health during pregnancy, diets, and lifestyles are more dominant in contributing to the new events of diabetes [3].

Genetic and environmental factors interact, drive the gene expression, and lead to certain phenotypes. The interaction between environment and gene is called epigenetics [4], and one of the most studied epigenetic mechanisms is DNA methylation. DNA methylation refers to the addition of a methyl group to the cytosine residues located on the $\mathrm{CpG}$ sites in the DNA [5]. This type of methylation in the promoter of the gene may lead to the gene repression since its pattern regulates specific gene expression in a specific cell at a certain time. Thus, the regulation of methylation level can meet normal metabolism process.

Aberrant DNA methylation pattern causes abnormal gene expression and leads to diseases, such as diabetes [6]. Our previous study showed that aberrant high DNA methylation levels in the placenta independently correlated with gestational diabetic mothers [4]. Aberrant DNA methylation pattern of specific genes is also reported to have affected the metabolic activity [7].

One of the reasons for diabetes is the imbalance between energy production and its consumption. Less energy consumption leads to the new onset of diabetes. Cells have the flexibility to select and to transform the sources of energy based on the availability of the sources in the body [8]. These cells tend to use glucose as an energy source once the cells have rich glucose environment. Conversely, when there is no glucose intake for some time, the cell breaks lipid molecules to generate energy. Failure of cell flexibility in transforming glucose into lipid as energy source molecule may lead to serious health problems followed with several symptoms such as insulin resistance and hyperglycemia which serve as the markers of diabetes [9].

One enzyme that plays an important role in maintaining cell flexibility between glucose and lipid molecule as an energy source is the pyruvate dehydrogenase complex (PDC) [10]. This enzyme plays a role in the decarboxylation of pyruvate into acetyl-CoA which is a molecule that can enter the citric acid cycle. PDC is an enzyme that can link glucose to lipid metabolism. The increased activity of the PDC enzyme can reduce glucose levels by accelerating the formation of pyruvic acid to acetyl-CoA which will produce energy after the citric acid cycle. Conversely, in low glucose levels, PDC activity is also low, and acetyl-CoA is mostly produced by the oxidation of free fatty acids as a result of lipolysis.

The PDC activity is regulated by the pyruvate dehydrogenase kinase (PDK) through the regulation of the phosphor level in PDC. Currently, there are several PDK enzymes that work specifically in different tissues [11]. The previous study showed that excessive expression of $P D K 4$ causes hyperglycemia and is associated with diabetes [12]. Furthermore, animal studies show that a high-fat diet correlates with a high level of fasting blood sugar concentration. Conversely, animals with high-fat diet can keep the normal sugar levels when the expression of PDK4 is simultaneously suppressed. This shows that PDK4 expression is essential to the contribution of hyperglycemia in the individual diabetes through the maintenance of the balanced expression in using glucose or lipid molecules as energy sources [12].

The previous study showed that the PDK4 methylation in the 5' UTR decreases, and the expression is increased in the patients' obesity from the blood sample [13]. Other studies have shown an increase in metabolism of $P D K 4$ in patients undergoing gastric bypass to control body weight. As seen there, epigenetic regulation plays a role in the weight of the patients with gastric bypass [14]. Direct observation was conducted by Kulkarni et al. who reduced methylation and increased expression of PDK4 in diabetic patients from the muscle sample [15]. However, the abovementioned studies have so far been confined to the exploration of the correlation between diabetes and the PDK4 methylation level. In contrast, further exploration 
of the first-onset phenotype between hyperglycemia as a symptom of diabetes and aberrant methylation pattern of PDK4 is required. The aim of this study is to answer whether the aberrant methylation pattern of $P D K 4$ or hyperglycemia is the first detected phenotype in the diabetic mouse model. The study is designed to increase the savior of diabetes using periodic streptozotocin (STZ) injection to mouse models. The blood sample was periodically taken until the hyperglycemia was observed. DNA methylation was determined afterwards.

\section{Method}

\section{Animal Experiment}

The experimental procedures have passed the guidelines of institutional ethical committee, University of Surabaya, Indonesia (No. 012/KE/III/2018). This research used experimental animals of 5-week-old male Swiss Webster mice that have almost the same weight. There were two groups: the control $(n=8)$ and the STZ $(n=7)$ groups. Both groups were fed with common pellet diet. The STZ group underwent the STZ injection $60 \mathrm{mg} / \mathrm{kg}$ body weight intraperitoneally [16]. The injection was carried out from the 5th week of the experiment and repeated weekly until the 9th week of the experiment to develop type 2 diabetes mellitus (T2D) mice. Blood sampling was carried out at the beginning of the experiment and repeated every 3 weeks until the end of the experiment within the same hour. The sampling schedule and the STZ injection can be seen in Fig. 1. At the end of the experiment, the mice were sacrificed. Then, blood and muscle samples were taken.

\section{Glucose Tolerance Test}

Glucose tolerance tests were carried out orally using the previous study as the reference [17]. The glucose dose was given at $2 \mathrm{~g}$ glucose $/ \mathrm{kg}$ of body weight. Blood sugar levels were determined after $0,15,30,60$, and 120 min prior to oral gavage glucose solution. A total of $0.3 \mu \mathrm{l}$ of blood samples was needed for blood measurement using a digital blood sugar measuring device. Blood samples were taken from the tail vein. The tail was wiped with EtOH $70 \%$. Blood was collected from the tip of the mice's tail by scarring using scissor, and the blood was drip on the autocheck® glucometer.

\section{Determination of Methylation Level}

With the exception of the last week of experiment in which the muscle and blood samples were obtained by animal sacrifice, blood sampling was carried out for every 3 weeks to observe the

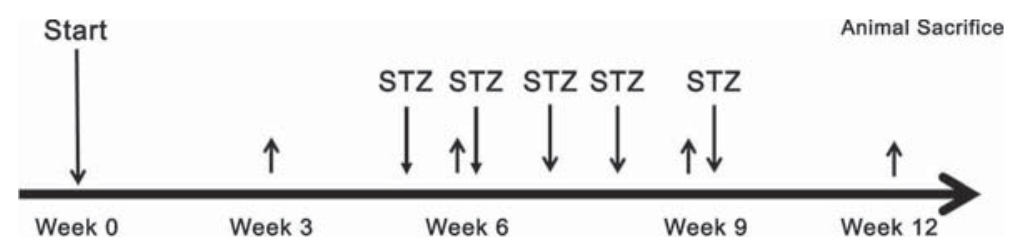

Fig. 1 Sampling schedule (upwards arrow) and injection of STZ (downwards arrow). The horizontal arrow indicates the time of sampling and STZ injection. Week 0 to week 12 indicated the week of experiments 
methylation dynamics of $P D K 4$. Blood was sampled by retroorbital from the venous sinus and collected in an EDTA tube. Methylation level was determined using several steps starting with the isolation of the DNA continued with the bisulfite treatment of the DNA samples [18], the amplification of bisulfite-treated DNA in the PDK4 promoter segment (Fig. 2), and finally the quantification of the treated DNA using specific software performed using several primers listed in Table 1.

\section{DNA Isolation}

DNA isolation was performed in several samples including the blood, pancreas, and muscle. The isolation was carried out using a commercially DNA isolation kit according to the method developed by the kit manufacturer (Tiangen®).

\section{Bisulfite Treatment}

Bisulfite treatment was carried out using a Zymo research bisulfite conversion kit. The DNA conversion was carried out based on the procedures developed by the kit sales company. In general, $500 \mathrm{ng}$ of DNA reacted with bisulfite to convert the cytosine base into thymine resulting in $10 \mu \mathrm{l}$ of the converted DNA solution in the end.

\section{Primer Design}

The design of the methyl-specific PCR (MSP) primer was carried out at the PDK4 promoter area (Mus musculus PDK4 gene Locus AF239176). This locus included the regulatory element or promoter for $2312 \mathrm{bp}$, followed with the untranslated region, and the coding sequences until $15,534 \mathrm{bp}$. The primer was designed to be the promoter to yield important $\mathrm{CpG}$ for PDK4 expression regulation. Prior to designing the primer, bioinformatics analysis was performed to search for certain cofactor binding sides in the promoter area. The primer was designed to cover the amplification of the important area of $P D K 4$ promoter. The amplified area is displayed in Fig. 2. Three $\mathrm{CpG}$ sites were targeted in this study: CpG site 1 (the 1855th sequence), CpG site 6 (the 1922nd sequence), and CpG site 7 (the 1969th sequence). PCR was performed using optimal condition to meet the requirements of the DNA denaturation and extension. The annealing temperature for every primer is listed in Table 1.

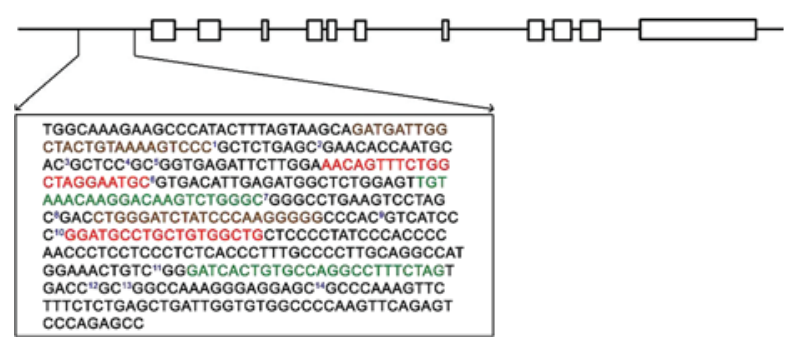

Fig. 2 Schematic diagram of PDK4 promoter area (regions 1802-2215) where targeted CpG sites were located. Brown letters are the primer sequence used for $\mathrm{CpG}$ site 1 methylation determination. Red and green letters represent the sequences of the primer used in the determination of CpG site 6 and CpG 7 methylation levels, respectively 
Table 1 Primers used in the study

\begin{tabular}{llll}
\hline No. & Primer name & Sequence & $T_{\text {annealing }}$ \\
\hline 1 & D-F_MSP_Met_PDK4 & TAAATAAGGATAAGTTTGGGC & $51{ }^{\circ} \mathrm{C}$ \\
2 & D-F_MSP_Non_PDK4 & TAAATAAGGATAAGTTTGGGT & \\
3 & D-R_MSP_PDK4 & CTAAAAAAACCTAACACAATAATC & $53{ }^{\circ} \mathrm{C}$ \\
4 & F-F_MSP_Met_PDK4 & GATGATTGGTTATTGTAAAAGTTTC & \\
5 & F-F_MSP_Non_PDK4 & GATGATTGGTTATTGTAAAAGTTTT & $51{ }^{\circ} \mathrm{C}$ \\
6 & F-R_MSP_PDK4 & CCCCCTTAAAATAAATCCCAA & \\
7 & S-F_MSP_Met_PDK4 & AATAGTTTTTGGTTAGGAATGC & $55^{\circ} \mathrm{C}$ \\
8 & S-F_MSP_Non_PDK4 & AATAGTTTTTGGTTAGGAATGT & \\
9 & S-R_MSP_PDK4 & CAACCACAACAAACATCC & \\
10 & F1_PDK4_Outer & AAGGGGGATTATAGGGTTAGTTAA & \\
11 & R1_PDK4_Outer & CTTAAAACCACACCAATCAACTC & \\
\hline
\end{tabular}

\section{Methylation Quantification}

Methylation level was quantified based on band density of the MSP result with alpha ease expressed in the following formula:

$$
\% \text { Methylation }=\frac{\text { The band intensity of MSP methylated } \mathrm{CpG} \text { site }}{\text { The band intensity of MSP non-methylated CpG site }}
$$

\section{PDK4 Expression Quantification}

PDK4 gene expression was quantified from the muscle organ samples of both the control and STZ groups obtained from the last week of experiment through animal sacrifice. Muscle was frozen in liquid nitrogen and powdered using organ pulverizer. Total RNA of the muscle organ was isolated using a protocol based on FavorPrep ${ }^{\text {TM }}$ Tissue Total RNA Mini Kit (Favorgen ${ }^{\circledR}$ ). cDNA was made using oligo (dT) and random hexamer concepts and carried out using protocol based on ExcelRT ${ }^{\mathrm{TM}}$ Reverse Transcription Kit II (SMOBIOß). qPCR was done by mixing 10 times diluted cDNA with SYBR Green and Primers (F-primer: 5'-ACTA GTGATGTGCGTGAGGC-3'; R-primer: 5'-CTTCCCTCGCTCCTCGTTTT-3'). cDNA was initially denatured $\left(95^{\circ} \mathrm{C}, 3 \mathrm{~min}\right)$ followed by 40 cycles of denaturation $\left(95^{\circ} \mathrm{C}, 10 \mathrm{~s}\right)$, annealing $\left(60{ }^{\circ} \mathrm{C}, 10 \mathrm{~s}\right)$, and elongation $\left(72{ }^{\circ} \mathrm{C}, 15 \mathrm{~s}\right)$. RT-qPCR assays were carried out using MyGoPro real-time PCR instrument. $\triangle \mathrm{Ct}$ of both the control and STZ groups was measured by differentiating PDK4 $\mathrm{Ct}$ and GAPDH $\mathrm{Ct}$ as the endogenous control. $\Delta \Delta \mathrm{Ct}$ was measured by differentiating the $\Delta \mathrm{Ct}$ sample and $\Delta \mathrm{Ct}$ mean of the control. PDK4 expression of the control group was normalized by using $\Delta \Delta \mathrm{Ct}$ calibrator measurement. Each sample was measured thrice. Data were represented in relative quantification ( $\mathrm{rq}$ ) with a formula of $2^{-\Delta \Delta \mathrm{Ct}}$.

\section{Statistical Analysis}

Statistical analysis was conducted by comparing certain data in two groups, namely, the control group and STZ group. Normality test was determined by the Shapiro-Wilk test at $P>0.05$ while the homogenous of the data variances was analyzed by Levene's test. All experiment data was analyzed for the significant difference using Student's $t$ test with the $P$ values written in the table and figure description. The statistical analysis was performed using SPSS version 22. 


\section{Results}

This study was designed to determine the first observed phenotype between hyperglycemia and aberrant methylation at the PDK4 promoter area. To achieve this goal, the fasting glucose level of the control group and the STZ animal experiment group was observed and recorded every 3 weeks. Once the difference of the fasting glucose levels was obtained, the glucose tolerance test was performed to further confirm the glucose performance in the mice. Figure 3 shows the fasting glucose level difference between the control and the STZ groups. The STZ group yielded significantly higher glucose levels since week 9 , and this continued to the 12th week of the experiment. Moreover, glucose tolerance test results from week 9 support the fact that in every time point post glucose injection, the blood glucose level of the STZ group is always significantly higher compared with that of the control group (Table 2). The similar trend was observed in the 12th week of the experiment (Table 3).

The next step in this study is to determine the level of methylation using the MSP method. CpG sites 1, 6, and 7 were located at the PDK4 promoter area. Nested PCR was designed to generate optimal MSP result of 179 bp of amplicon length for $\mathrm{CpG}$ site 1, whereas amplicon lengths for CpG site 6 and CpG site 7 detection were 142 and 190 bp, respectively (Fig. 4).

The dynamics of the methylation level during the experiment was shown in Fig. 4. No significant difference was observed in week 0 and week 3 between the control group and the STZ group. However, it is interesting that only the methylation level from CpG site 6 is different between the control group and the STZ group in week 6 (Fig. 5). The difference of the methylation levels in $\mathrm{CpG}$ site 6 was firstly observed and compared with the significant difference of the fasting glucose levels firstly observed in the 9th week of the experiment. Moreover, there was no significant difference in $\mathrm{CpG}$ site 1 and $\mathrm{CpG} 7$ methylation levels between the control group and the STZ group along the experiment time (Fig. 5).

DNA methylation level is unique for every different cell. PDK4 is an enzyme that is actively expressed in muscles and helps regulate blood sugar levels by keeping the PDK4 expression levels low. The above results show that the methylation level of $\mathrm{CpG}$ site 6 of blood cells is significantly higher in the STZ group compared with that in the control group. However, we found no significance on methylation level of $\mathrm{CpG}$ site $1, \mathrm{CpG}$ site 6, and CpG site 7 of the muscle cells (Fig. 6). The trend of lower methylation level of the STZ group compared with that of the control group was observed, but it did not reach the significant level.

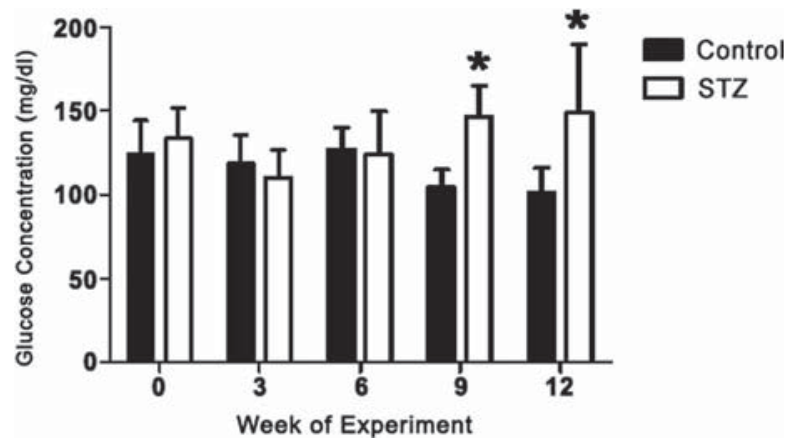

Fig. 3 Fasting blood glucose level on different weeks during the experiment (control group, $n=8$; STZ group, $n=7$ ). The comparison between the averages of the glucose concentration for each week of the experiment was analyzed using $t$ test, $* P<0.05$ 
Table 2 Glucose tolerance test of week 9 experiment

\begin{tabular}{|c|c|c|c|c|c|}
\hline \multirow[t]{2}{*}{ Treatment } & \multicolumn{5}{|c|}{ Glucose concentration $(\mathrm{mg} / \mathrm{dl})$ at a certain time (in minutes) after oral glucose intervention } \\
\hline & $0 \mathrm{~min}$ & $15 \mathrm{~min}$ & $30 \mathrm{~min}$ & $60 \mathrm{~min}$ & $120 \mathrm{~min}$ \\
\hline Control & $100.6^{\mathrm{a}} \pm 11.8$ & $184.8^{\mathrm{a}} \pm 38.1$ & $196.0^{\mathrm{a}} \pm 51.1$ & $129.4^{\mathrm{a}} \pm 34.9$ & $88.3^{\mathrm{a}} \pm 14.2$ \\
\hline STZ & $136.5^{\mathrm{b}} \pm 23.3$ & $286.5^{b} \pm 60.3$ & $344.6^{\mathrm{b}} \pm 93.9$ & $301.5^{\mathrm{b}} \pm 109.3$ & $156.3^{\mathrm{b}} \pm 61.9$ \\
\hline
\end{tabular}

Different superscript letters in different columns symbolize significantly different on the blood glucose level using $t$ test between the control and STZ groups at $P<0.05$ (control group, $n=8$; STZ group, $n=7$ )

However, the PDK4 expression in the muscle organ of the STZ group was significantly increased to about threefold compared with the control group (Fig. 7). The difference between methylation level and PDK4 expression might be because methylation level was analyzed using site-specific primers; thus, these primers cannot give a bigger picture of total methylation in PDK4 promoter. Nevertheless, increase of PDK4 expression in the muscle organ affirmed that hyperglycemia has occurred [12].

\section{Discussion}

This study shows that the periodic injection of the STZ can be used to generate hyperglycemia in the mouse model. Fasting blood glucose level was found significantly higher in the STZ group compared with that in the control group since the 9th week of the experiment. Fasting blood glucose concentration in the STZ group continued to increase at the end of the 12th week of the experiment. The observation of methylation dynamics during the experiment revealed a continuous increase of PDK4 promoter area methylation in the STZ group. The comparison of the methylation level between the STZ group and the control group resulted in significantly higher methylation of $\mathrm{CpG}$ site 6 at the promoter area of $P D K 4$ observed during the 6th week of the experiment. No significant difference was found between the STZ group and the control group on $\mathrm{CpG}$ site 1 and $\mathrm{CpG}$ site 7 at the $P D K 4$ promoter area. There was also a positive correlation between the methylation level of $\mathrm{CpG}$ site 6 and the blood glucose concentration.

Hyperglycemia was observed in the STZ group after the STZ multiple injections. This result was in accordance with the results of several previous studies [19-21]. The gradual injection leads to the gradual damage to the pancreatic beta cells by means of necrosis. In the previous study, the multiple injections were used to develop type 2 diabetes mellitus (T2D) in combination with the diet on an animal experiment model [22]. Gradual damage in pancreatic beta cells due to multiple STZ injections is expected to mimic the physiological effects of $\mathrm{T} 2 \mathrm{D}$ individuals who experience

Table 3 Glucose tolerance test of week 12 experiment

\begin{tabular}{|c|c|c|c|c|c|}
\hline \multirow[t]{2}{*}{ Treatment } & \multicolumn{5}{|c|}{ Glucose concentration $(\mathrm{mg} / \mathrm{dl})$ at a certain time (minutes) after oral glucose intervention } \\
\hline & $0 \mathrm{~min}$ & $15 \mathrm{~min}$ & $30 \mathrm{~min}$ & $60 \mathrm{~min}$ & $120 \mathrm{~min}$ \\
\hline Control & $97.9^{\mathrm{a}} \pm 12.7$ & $179.7^{\mathrm{a}} \pm 50.4$ & $134.6^{\mathrm{a}} \pm 35.5$ & $115.6^{\mathrm{a}} \pm 26.1$ & $91.3^{\mathrm{a}} \pm 16.1$ \\
\hline STZ & $167.4^{b} \pm 75.0$ & $311.2^{b} \pm 69.9$ & $329.6^{b} \pm 90.2$ & $297.2^{\mathrm{b}} \pm 125.0$ & $212.4^{\mathrm{b}} \pm 125.0$ \\
\hline
\end{tabular}

Different superscript letters in different columns symbolize significantly different on the blood glucose level using $t$ test at $P<0.05$ (control group, $n=8$; STZ group, $n=7$ ) 


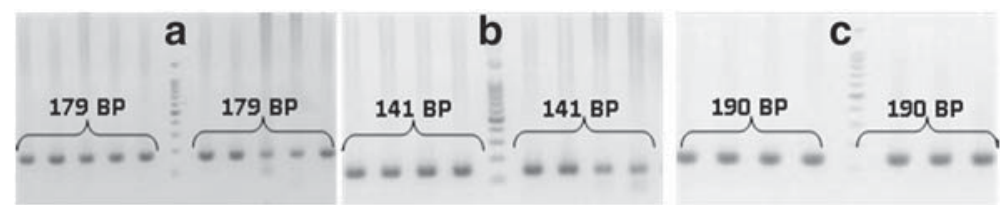

Fig. 4 MSP result of $\mathrm{CpG}$ site $1, \mathrm{CpG}$ site 6 , and $\mathrm{CpG}$ site 7 of $P D K 4$ area promoter (A, B, and C, respectively)

increased damage in their pancreatic beta cells over time. Another method to achieve hyperglycemia is by using single high-dosed STZ injection. A single STZ injection in large doses may generate adequate levels of pancreatic beta cell damage at once and lead to hyperglycemia. Large doses of a single STZ injection are not applicable here since this study requires only a slight increment in glucose concentration during the experimental time to achieve the purpose of the study.

In this study, $\mathrm{CpG}$ site 6 methylation level at the $P D K 4$ promoter area was significantly higher in the STZ group than that in the control group. This difference was initially observed during the 6 th week of the experiment -3 weeks prior to the 9 th week which was the initial development of hyperglycemia. There was no significant difference on $\mathrm{CpG}$ site 1 and $\mathrm{CpG}$ site 7 methylation levels between the STZ group and the control group. However, the methylation level on $\mathrm{CpG}$ site 6 was increased until the 12th week of the experiment. de la Rocha et al. used 5 sites of CpG of 5' UTR of PDK4 from blood samples of overweight patients as a target of interest [13]. In contrast, Kulkarni et al. analyzed the muscle sample of $P D K 4$ promoter region +160 to +446 from T2D patients [15] and reported a reduction in the methylation level. Another study also showed that only one out four loci in PDK4 gene was
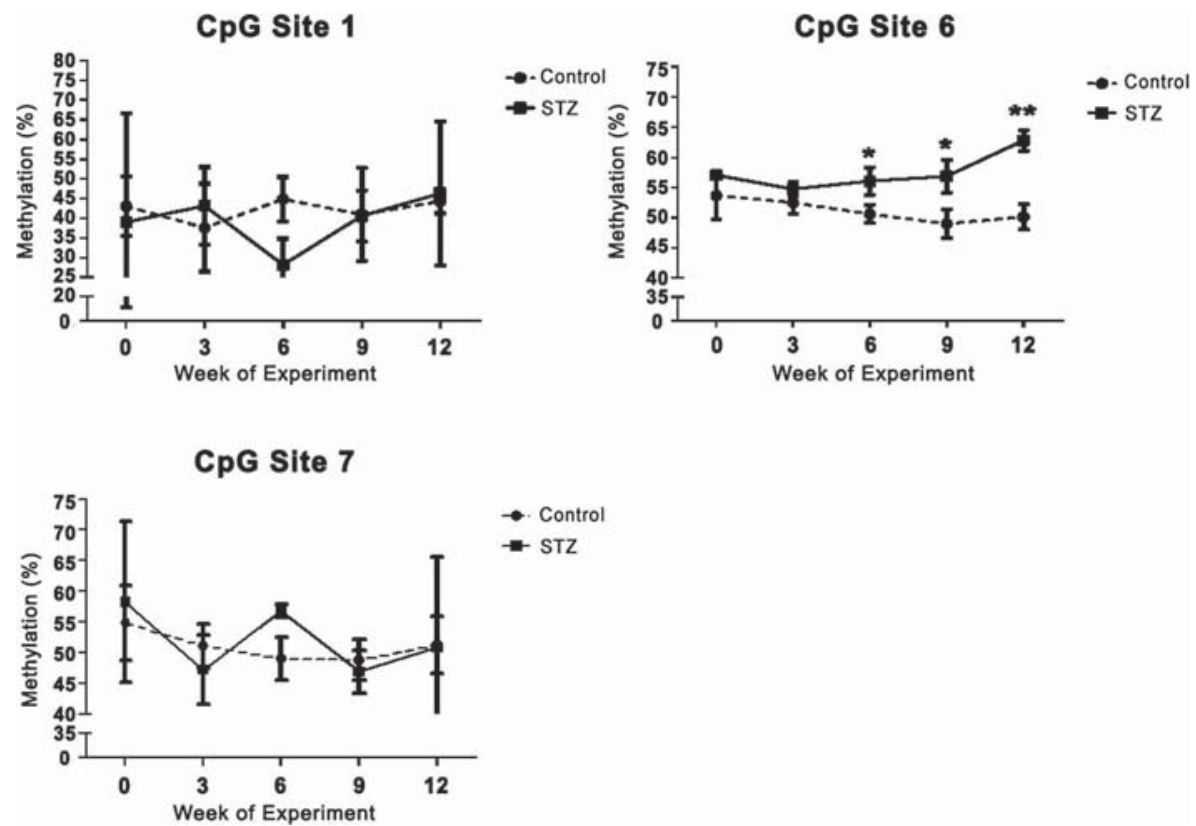

Fig. 5 Methylation dynamics of $\mathrm{CpG}$ site $1, \mathrm{CpG}$ site 6 , and $\mathrm{CpG}$ site 7 during the experiment (control group, $n=8$; STZ group, $n=7$ ). Comparison between the averages of the methylation level for each week of the experiment was analyzed using $t$ test. $* P<0.05$, $* * P<0.01$ 

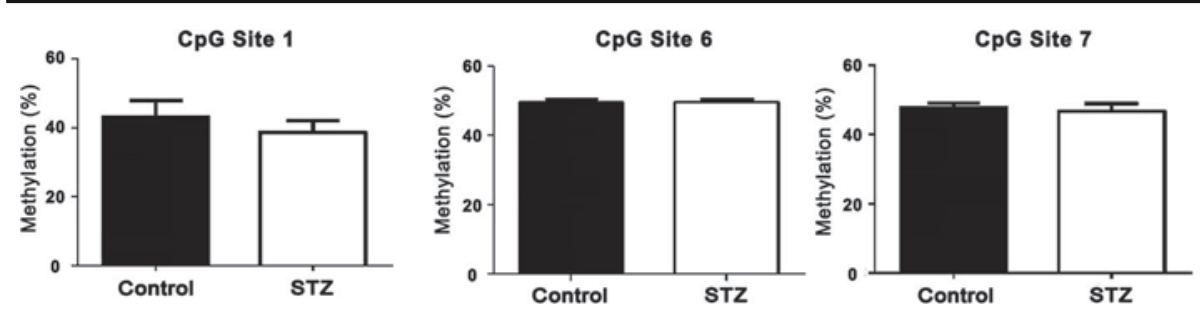

Fig. 6 Methylation level of CpG site $1, \mathrm{CpG}$ site 6, and $\mathrm{CpG}$ site 7 of $P D K 4$ promoter of the muscle cell at week 12 of the experiment (control group, $n=8$; STZ group, $n=7$ ). Comparison between the averages of the methylation level was analyzed using $t$ test. $P<0.05$

significantly reduced [23]. The different trend compared with some previous studies could be due to the difference between the analyzed region and the cell sample [24].

Nevertheless, since the significant difference of the blood glucose level between the STZ group and the control group was observed during the 9 th week of the experiment, this result gives insight to the use of $\mathrm{CpG}$ site 6 methylation level as a molecular marker of hyperglycemia. The previous study had reported candidate gene methylation or global methylation that could be used as a molecular marker for diabetes. The aberrant methylation of TCF7L2, KCNQ1, ABCG1, TXNIP, PHOSPHO1, SREBF1, SLC30A8, and FTO in the blood cells was reproducibly associated with diabetes [25]. Global methylation of pancreatic cells was also shown to be associated with diabetes [4]. However, most of the studies were only performed in the correlation analysis method. The report in this study which shows that aberrant methylation of $P D K 4$ came before hyperglycemia can be very useful to anticipate the upcoming unfavorable events. This experiment result benefits the impacted individuals through the management of their diets or lifestyles in order to avert hyperglycemia.

$P D K 4$ is a gene that is expressed in pancreatic cells slightly and in several other cells such as the muscles, brain, liver, lungs, and kidneys. Mostly, the active site of PDK4 is the muscle cell. PDK4 activated the $\beta$-oxidation pathway and could be repressed by insulin. However, PDK4 is used to maintain homeostasis between glucose and fat levels while in short-term fat diet, increase of PDK4 expression helped to protect muscle cells from fatty acid-induced oxidative stress [26]. PDK4 works effectively in muscle cells to remove glucose from the bloodstream. Methylation is specifically considered for use in different cells, and the methylation analysis was conducted to

Fig. $7 P D K 4$ expression in the muscle organ at week 12 of the experiment analyzed with RTqPCR (control group, $n=4$; STZ group, $n=5$ ). Comparison between the averages of the PDK4 expression was analyzed using $t$ test. $* * P<0.0$
PDK4 Expression in Muscle

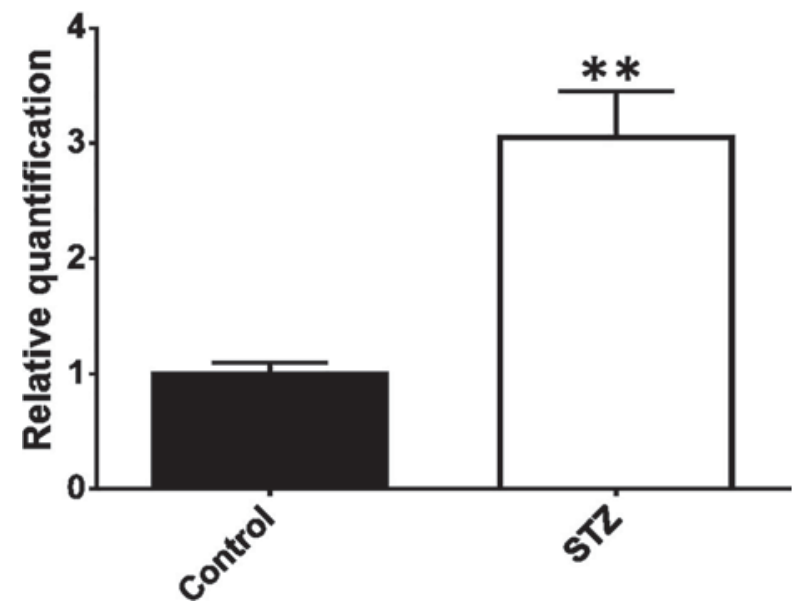


analyze muscle cells. There was no significant reduction in the methylation level at the PDK4 promoter area between the STZ group and the control group. Regulatory damage to PDK4 expression in the muscle cells is associated with insulin resistance [27]. Although the reduction in the methylation level was not observed in this study, PDK4 expression in the muscle sample was repressed in the STZ group compared with the control group. This difference can be explained since our study employed the specific-site PCR of bisulfite conversion, in contrast to bisulfite sequencing which could read whole regulatory sequence [28]. Only three $\mathrm{CpG}$ sites were analyzed through numerous $\mathrm{CpG}$ sites in the PDK4 promoter.

The investigation of metabolic-related gene expression and methylation such as PDK4 in blood can potentially result in a production of marker for early detection of metabolic disorder. The blood PDK4 promoter methylation level and PDK4 expression in the muscle sample were not coherent. However, this might be because one protein behaves differently in different organs. $S c d l$ overexpression in the liver was associated with insulin resistance [29]. In contrast, activation of $S c d l$ in the skeletal muscle cell induced fatty acid oxidation and increased cell metabolism, thus protecting mice from getting obese [30]. Previous study stated that methylation at a specific locus of $A B C G 1$ positively correlated with the future risk of diabetes mellitus. This result is in contrast with the methylation that negatively correlated at specific $\mathrm{CpG}$ locus of $\mathrm{PHOSPHOI}$ [23]. One of the $\mathrm{CpG}$ loci in the $P P A R \gamma$ and two CpG loci FTO from peripheral blood cells showed almost a significant methylation increase in T2D-diagnosed people [24].

CpG site 6 of $P D K 4$ methylation level in blood cell and the blood glucose level observed in this study correlate positively. Furthermore, the methylation had appeared before the hyperglycemia period occurred. This occurrence indicated the mechanistic link between the methylation level of CpG site 6 at the $P D K 4$ promoter of blood cell and the blood glucose concentration. Further studies, however, are needed to determine the mechanistic link between PDK4 methylation level of blood cell and hyperglycemia.

\section{Conclusion}

Changes in the methylation at the PDK4 promoter area of blood cells successfully occurred before the observation of hyperglycemia in the STZ group compared with those in the control group. No methylation level difference was observed between the STZ group and the control group in muscle cells.

Funding Information This research was supported by PT Nutrifood Indonesia according to research grant no. SP/LG NFI-17/171 and Indonesia Ministry of Research, Technology, and Higher Education (021/SP-Lit/LPPM01/DRPM/Multi/FTB/III/2019).

Compliance with Ethical Standards The experimental procedures have passed the guidelines of institutional ethical committee, University of Surabaya, Indonesia (No. 012/KE/III/2018).

Conflict of Interest The authors declare that they have no conflict of interest.

\section{References}

1. Cho, N. H., Shaw, J. E., Karuranga, S., Huang, Y., da Rocha Fernandes, J. D., Ohlrogge, A. W., \& Malanda, B. (2018). IDF diabetes atlas: global estimates of diabetes prevalence for 2017 and projections for 2045. Diabetes Research and Clinical Practice, 138, 271-281. 
2. Das, S. K., \& Elbein, S. C. (2006). The genetic basis of type 2 diabetes. Cellscience., 2(4), 100-131

3. Kolb, H., \& Martin, S. (2017). Environmental/lifestyle factors in the pathogenesis and prevention of type 2 diabetes. BMC Medicine, 15(1), 131.

4. Reichetzeder, C., Dwi Putra, S. E., Li, J., \& Hocher, B. (2016). Developmental origins of disease - crisis precipitates change.Cellular Physiology and Biochemistry, 39(3), 919-938.

5. Mamrut, S., Harony, H., Sood, R., Shahar-Gold, H., Gainer, H., Shi, Y.-J., et al. (2013). DNA methylation of specific $\mathrm{CpG}$ sites in the promoter region regulates the transcription of the mouse oxytocin receptor. PLoS One, $8(2)$, e56869.

6. Chen, X., Liu, L., Mims, J., Punska, E. C., Williams, K. E., Zhao, W., et al. (2015). Analysis of DNA methylation and gene expression in radiation-resistant head and neck tumors. Epigenetics., 10(6), 545-561.

7. Shao, W.-J., Tao, L.-Y., Gao, C., Xie, J.-Y., \& Zhao, R.-Q. (2008). Alterations in methylation and expression levels of imprinted genes H19 and Igf2 in the fetuses of diabetic mice. Comparative Medicine, 58(4), 341346.

8. Pang, J., Xi, C., Huang, X., Cui, J., Gong, H., \& Zhang, T. (2016). Effects of excess energy intake on glucose and lipid metabolism in C57BL/6 mice. PLoS One, 11(1), e0146675.

9. Galgani, J. E., Moro, C., \& Ravussin, E. (2008). Metabolic flexibility and insulin resistance. The American Journal of Physiology - Endocrinology and Metabolism, 295(5), E1009-E1017.

10. Tareen, S. H., Kutmon, M., Adriaens, M. E., Mariman, E. C., de Kok, T. M., Arts, I. C., \& Evelo, C. T. (2018). Exploring the cellular network of metabolic flexibility in the adipose tissue. Genes \& Nutrition, 13(1), 17.

11. Zhang, S., Hulver, M. W., McMillan, R. P., Cline, M. A., \& Gilbert, E. R. (2014). The pivotal role of pyruvate dehydrogenase kinases in metabolic flexibility. Nutrition and Metabolism, 11, 10.

12. Jeoung, N. H., \& Harris, R. A. (2010). Role of pyruvate dehydrogenase kinase 4 in regulation of blood glucose levels. Korean Diabetes Journal, 34(5), 274-283.

13. de la Rocha, C., Pérez-Mojica, J. E., León, S. Z.-D., Cervantes-Paz, B., Tristán-Flores, F. E., RodríguezRíos, D., et al. (2016). Associations between whole peripheral blood fatty acids and DNA methylation in humans. Scientific Reports, 6:25867.

14. Kirchner, H., Nylen, C., Laber, S., Barrès, R., Yan, J., Krook, A., et al. (2014). Altered promoter methylation of PDK4, IL1 B, IL6, and TNF after Roux-en Y gastric bypass. Surgery for Obesity and Related Diseases, (4), 671-678.

15. Kulkarni, S. S., Salehzadeh, F., Fritz, T., Zierath, J. R., Krook, A., \& Osler, M. E. (2012). Mitochondrial regulators of fatty acid metabolism reflect metabolic dysfunction in type 2 diabetes mellitus. Metabolism., 61(2), 175-185.

16. Wang, K., Tang, Z., Zheng, Z., Cao, P., Shui, W., Li, Q., \& Zhang, Y. (2016). Protective effects of Angelica sinensis polysaccharide against hyperglycemia and liver injury in multiple low-dose streptozotocin-induced type 2 diabetic BALB/c mice. Food \& Function, 7(12), 4889-4897.

17. Andrikopoulos, S., Blair, A. R., Deluca, N., Fam, B. C., \& Proietto, J. (2008). Evaluating the glucose tolerance test in mice. American Journal of Physiology. Endocrinology and Metabolism, 295(6), E1323E1332.

18. Yang, A. S., Estécio, M. R., Doshi, K., Kondo, Y., Tajara, E. H., \& Issa, J. P. J. (2004). A simple method for estimating global DNA methylation using bisulfite PCR of repetitive DNA elements. Nucleic Acids Research, 32(3), e38-e38.

19. Chaudhry, Z. Z., Morris, D. L., Moss, D. R., Sims, E. K., Chiong, Y., Kono, T., \& Evans-Molina, C. (2013). Streptozotocin is equally diabetogenic whether administered to fed or fasted mice. Laboratory Animals, 47(4), 257-265.

20. Furman, B. L. (2015). Streptozotocin-induced diabetic models in mice and rats. Current Protocols in Pharmacology, 70(1), 5-47.

21. Vatandoust, N., Rami, F., Salehi, A. R., Khosravi, S., Dashti, G., Eslami, G., Momenzadeh, S., \& Salehi, R. (2018). Novel high-fat diet formulation and streptozotocin treatment for induction of prediabetes and type 2 diabetes in rats. Advanced Biomedical Research, 7, 107.

22. Barrière, D. A., Noll, C., Roussy, G., Lizotte, F., Kessai, A., Kirby, K., Belleville, K., Beaudet, N., Longpré, J. M., Carpentier, A. C., Geraldes, P., \& Sarret, P. (2018). Combination of high-fat/high-fructose diet and low-dose streptozotocin to model long-term type-2 diabetes complications. Scientific Reports, 8(1), 424.

23. Dayeh, T., Tuomi, T., Almgren, P., Perfilyev, A., Jansson, P. A., de Mello, V. D., Pihlajamaki, J., Vaag, A., Groop, L., Nilsson, E., \& Ling, C. (2016). DNA methylation of loci within ABCG1 and PHOSPHO1 in blood DNA is associated with future type 2 diabetes risk. Epigenetics., 11(7), 482-488.

24. van Otterdijk, S. D., Binder, A. M., vel Szic, K. S., Schwald, J., \& Michels, K. B. (2017). DNA methylation of candidate genes in peripheral blood from patients with type 2 diabetes or the metabolic syndrome. PLoS One, 12(7), e0180955. 
25. Willmer, T., Johnson, R., Louw, J., \& Pheiffer, C. (2018). Blood-Based DNA Methylation biomarkers for type 2 diabetes: potential for clinical applications. Frontiers in Endocrinology, 9, 744.

26. Chokkalingam, K., Jewell, K., Norton, L., Littlewood, J., Van Loon, L. J. C., Mansell, P., MacDonald, I. A., \& Tsintzas, K. (2007). High-fat/low-carbohydrate diet reduces insulin-stimulated carbohydrate oxidation but stimulates nonoxidative glucose disposal in humans: an important role for skeletal muscle pyruvate dehydrogenase kinase 4. The Journal of Clinical Endocrinology and Metabolism, 92(1), 284-292.

27. Zhou, Z., Sun, B., Li, X., \& Zhu, C. (2018). DNA methylation landscapes in the pathogenesis of type 2 diabetes mellitus. Nutrition \& Metabolism (London), 15, 47.

28. Kurdyukov, S., \& Bullock, M. (2016). DNA methylation analysis: choosing the right method. Biology., $5(1), 3$.

29. Drąg, J., Goździalska, A., Knapik-Czajka, M., Gawędzka, A., Gawlik, K., \& Jaśkiewicz, J. (2017). Effect of high carbohydrate diet on elongase and desaturase activity and accompanying gene expression in rat's liver. Genes \& Nutrition, 12(1), 2.

30. Rogowski, M. P., Flowers, M. T., Stamatikos, A. D., Ntambi, J. M., \& Paton, C. M. (2013). SCD1 activity in muscle increases triglyceride PUFA content, exercise capacity, and PPAR $\delta$ expression in mice. Journal of Lipid Research, 54(10), 2636-2646.

Publisher's Note Springer Nature remains neutral with regard to jurisdictional claims in published maps and institutional affiliations. 


\section{aberrant_pdk4_promoter_methyl ation.pdf \\ by Sulistyo Singajaya}

Submission date: 01-Feb-2021 02:07PM (UTC+0700)

Submission ID: 1498884929

File name: aberrant_pdk4_promoter_methylation.pdf (766.4K)

Word count: 5545

Character count: 29212 


\title{
Aberrant PDK4 Promoter Methylation Preceding Hyperglycemia in a Mouse Model
}

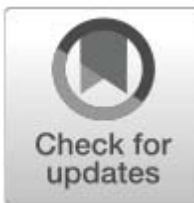

\section{Sulistyo Emantoko Dwi Putra 'ㄷ - Stephanie Singajaya ${ }^{1} \cdot$ Ferensia Thesman ${ }^{1}$. Dicky Andhika Pranoto ${ }^{1} \cdot$ Ricky Sanjaya ${ }^{1} \cdot$ Yoanes Maria Vianney ${ }^{1}$. Ida Bagus Made Artadana'}

\begin{abstract}
Diabetic prevalence is at speedy increase globally. Previous studies stated that other than genetics, factors such as environment, lifestyle, and paternal-matemal condition 14 critical roles in diabetes through DNA methylation in specific areas of the genome. The purpose of this study is to investigate the methylation pattern of the PDK4 promoter in streptozotocin-induced diabetic mice until the 12th week of the observation. The methylation pattern in the blood samples was analyzed periodically, while the pattem in the muscle sample was only analyzed at $t_{2}$ end of the experiment using the blood of the sacrificed animals. Three methylated CpG site $1, \mathrm{CpG}$ site $6{ }_{4}$ and $\mathrm{CpG}$ site 7 were analyzed and quantified based on the band density using bisulfite treatment and methylation-specific polymerase chain reaction (PCR). The hyperglycemia period was developed at the 9th week of experiment. However, there was a significant increase of methylation, specifically on CpG site 6 started from week 6 to week 12 . This peculiar methylation on $\mathrm{CpG}$ site $\epsilon_{40} P D K 4$ promoter in the blood sample before the hypergly28 ic period might serve as a potential biomarker for early detection of diabetes in the patients. No significant difference was found between the methylation level of streptozotocin (STZ)-treated mice and of the control group in the muscle sample.
\end{abstract}

Keywords Blood · Epigenetics $\cdot$ Methylation pattern $\cdot$ PDK4 $\cdot$ STZ-induced diabetic mice

\section{Introduction}

From 151 million in 2000 to 451 million in 2017, global diabetic prevalence has been an increasing trend [1]. Das and Elbein mentioned in their review that parental diabetes is descended on the

\section{2}

Sulistyo Emantoko Dwi Putra

emantoko@staff.ubaya.ac.id

I Department of Biology, Faculty of Biotechnology, University of Surabaya, Raya Kalirungkut, Surabaya, East Java 60292, Indonesia 
children through gene mutation [2]. Recent studies show that genetics is not the only factor in the emergence of diabetes. Environmental factors such as maternal health during pregnancy, diets, and lifestyles are more dominant in contributing to the new events of diabetes [3].

Genetic and environmental factors interact, drive the gene expression, and lead to cerigh phenotypes. The interaction between environment and gene is called epigenetics [4], and one of the most studied epigenetic mechanisms is DNA methylation. DNA methylation refers to the addition o 39 methyl group to the cytosine residues located on the CpG sites in the DNA [5]. This type of methylation in the promoter of the gene may lead to the gene repression since its pattern regulates specific gene expression in a specific cell at a certain time. Thus, the regulation of methylation level can meet normal metabolism process.

Aberrant DNA m 14 lation pattern causes abnormal gene expression and leads to diseases, such as diabetes [6]. Our previous study showed that aberrant high DNA methylation ler 27 in the placenta independently correlated with gestational diabetic mothers [4]. Aberrant DNA methylation pattem of specific genes is also reported to have affected the metabolic activity [7].

One of the reasons for diabetes is the imbalance between energy production and its consumption. Less energy consumption leads to the new onset of diabetes. Cells have the flexibility to select and to transform the sources of energy based on the availability of the sources in the body [8]. These cells tend to use glucose as an energy source once the cells have rich glucose environment. Conversely, when there is no glucose intake for some time, the cell breaks lipid molecules to generate energy. Failure of cell flexibility in transforming glucose into lipid as energy source molecule may lead to serious health problems followed with several symptoms such as insulin resistance and hyperg 38 emia which serve as the markers of diabetes [9].

One enzyme that plays an important role in maintaining cell flexibility between glucose and lipid molecule as an energy 17 urce is the pyruvate dehydrogenase complex (PDC) [10]. This enzyme plays a role in the decarboxylation of pyruvate into acetyl-CoA which is a molecule that can enter the citric acid cycle. PDC is an enzyme that can link glucose to lipid metabolism. The increased activity of the PDC enzyme can reduce glucose levels by accelerating the formation of pyruvic acid to acetyl-CoA which will produce energy after the citric acid cycle. Conversely, in low glucose levels, PDC activity is also low, and acetyl-CoA is mostly produce $17 \mathrm{y}$ the oxidation of free fatty acids as a result of lipolysis.

The PDC activity is regulated by the pyruvate dehydrogenase kinase (PDK) through the regulation of the phosphor level in PDC. Currently, there are several PDK enzymes that work specifically in different tissues [11]. The previous study showed that excessive expression of PDK4 causes hyperglycemia and is associated with diabetes [12]. Furthermore, animal studies show that a high-fat diet correlates with a high level of fasting blood sugar concentration. Conversely, animals with high-fat diet can keep the normal sugar levels when the expression of $P D K 4$ is simultaneously suppressed. This shows that PDK4 expression is essential to the contribution of hyperglycemia in the individual diabetes through the maintenance of the balanced expression in using glucose or lipid molecules as energy sources [12].

The previous study showed that the PDK4 methylation in the 5' UTR decrea 11 and the expression is increased in the patients' obesity from the blood sample [13]. Other studies have shown an increase in metabolism of PDK4 in patients undergoing gastric bypass to control body weight. As seen there, epigenetic regulation plays a role in the weight of the patients with gastric bypass [14]. Direct observation was conducted by Kulkarni et al. who reduced methylation and increased expression of PDK4 in diabetic patients from the muscle sample [15]. However, the abovementioned studies have so far been confined to the exploration of the correlation between diabetes and the PDK4 methylation level. In contrast, further exploration 
of the first-onset phenotype between hyper 26 remia as a symptom of diabetes and aberrant methylation pattern of $P D K 4$ is required. The aim of this study is to answer whether the aberrant methylation pattern of $P D K 4$ or hyperglycemia is the first detected phenotype in the diabetic mouse model. The study is designed to increase the savior of diabetes using periodic streptozotocin (STZ) injection to mouse models. The blood sample was periodically taken until the hyperglycemia was observed. DNA methylation was determined afterwards.

\section{Method}

\section{Animal Experiment}

The experimental procedures have passed the guidelines of institutional ethical committee, University of Surabaya, Indonesia (No. 012/KE/III/2018). This research used experimental animals of 5-weel $37-1$ male Swiss Webster mice that have almost the same weight. There were two groups: the control $(n=8)$ and the STZ $(n=7)$ groups. Both groups were fed with common pellet diet. The STZ group underwent the STZ injection $60 \mathrm{mg} / \mathrm{kg}$ body weight intraperitoneally [16]. The injection was carried out from 11 th week of the experiment and repeated weekly until the 9th week of the experiment to develop type 2 diabetes mellitus (T2D) n 36 . Blood sampling was carried out at the beginning of the experiment and repeated every 3 weeks until the end of the experiment 13 hin the same hour. The sampling schedule and the STZ injection can be seen in Fig. 1. At the end of the experiment, the mice were sacrificed. Then, blood and muscle samples were taken.

\section{2}

\section{Glucose Tolerance Test}

Glucose tolerance tests were carri 35 put orally using the previous study as the ref 24 ce [17]. The glucose dose was given at $2 \mathrm{~g}$ glucose/ $\mathrm{kg}$ of body weight. Blood sugar levels were determined after $0,15,30,60$, and $120 \mathrm{~min}$ prior to oral gavage glucose solution. A total of $0.3 \mu \mathrm{l}$ of blood s 34 les was needed for blood measurement using a digital blood sugar meast 13 device. Blood samples were taken from the tail vein. The tail was wiped with EtOH $70 \%$. Blood was collected from the tip of the mice's tail by scarring using scissor, and the blood was drip on the autocheck® glucometer.

\section{Determination of Methylation Level}

With the exception of the last week of experiment in which the muscle and blood samples were obtained by animal sacrifice, blood sampling was carried out for every 3 weeks to observe the

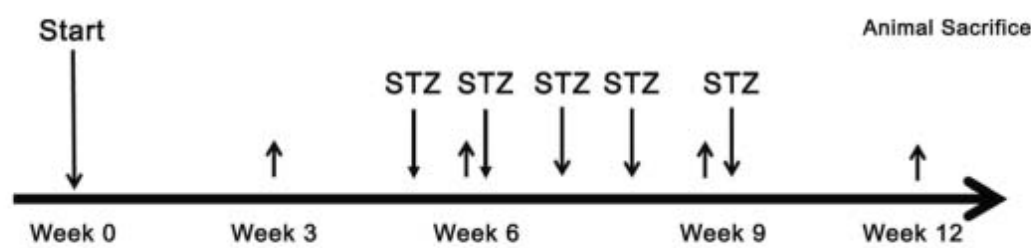

Fig. 1 Sampling schedule (upwards arrow) and injection of STZ (downwards arrow). The horizontal arrow indicates the time of sampling and STZ injection. Week 0 to week 12 indicated the week of experiments 
methylation dynamics of PDK4. Blood was sampled by retroorbital from the venous sinus and collected in an EDTA tube. Methylation level was determined using several steps starting with the isolation of the DNA continued with the bisulfite treatment of the DNA samples [18], the amplification of bisulfite-treated DNA in the PDK4 promoter segment (Fig. 2), and finally the quantification of the treated DNA using specific software performed using several primers listed in Table 1.

\section{DNA Isolation}

DNA isolation was performed in several samples including the blood, pancreas, and muscle. The isolation was carried out using a commercially DNA isolation kit according to the method developed by the kit manufacturer (Tiangen $\circledast$ ).

\section{Bisulfite Treatment}

Bisulfite treatment was carried out using a Zymo research bisulfite conversion kit. The DNA conversion was carried out based on the procedures developed by the kit sales company. In general, $500 \mathrm{ng}$ of DNA reacted with bisulfite to convert the cytosine base into thymine resulting in $10 \mu \mathrm{l}$ of the converted DNA solution in the end.

\section{Primer Design}

The design of the methyl-specific PCR (MSP) primer was carried out at the PDK4 promoter area (Mus musculus PDK4 gene Locus AF239176). This locus included the regulatory element or promoter for $2312 \mathrm{bp}$, followed with the untranslated region, and the coding sequences until $15,534 \mathrm{bp}$. The primer was designed to be the promoter to yield important CpG for PDK4 expression regulation. Prior to designing the primer, bioinformatics analysis was performed to search for certain cofactor binding sides in the promoter area. The primer was designed to cover the amplification of the important area of PDK4 promoter. The amplified area is displayed in Fig. 2. Three CpG sites were targeted in this study: CpG site 1 (the 1855 th sequence), CpG site 6 (the 1922 nd sequence), and CpG site 7 (the 1969th sequence). PCR was performed using optimal condition to meet the requirements of the DNA denaturation and extension. The annealing temperature for every primer is listed in Table 1.

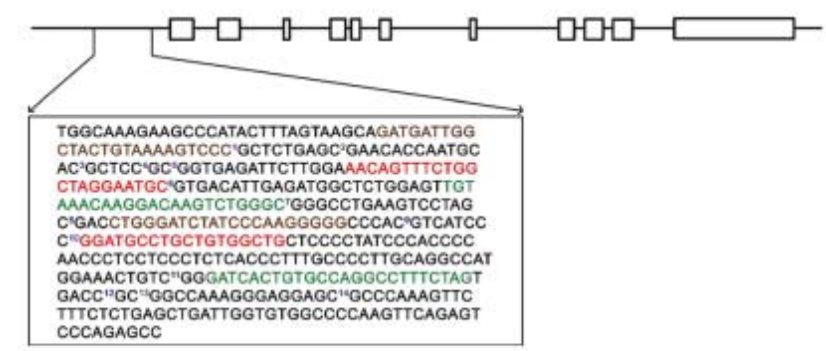

Fig. 2 Schematic diagram of $P D K 4$ promoter area (regions 1802-2215) where targeted CpG sites were located. Brown letters are the primer sequence used for $\mathrm{CpG}$ site 1 methylation determination. Red and green letters represent the sequences of the primer used in the determination of $\mathrm{CpG}$ site 6 and $\mathrm{CpG} 7$ methylation levels, respectively 
Table 1 Primers used in the study

\begin{tabular}{llll}
\hline No. & Primer name & Sequence & $T_{\text {annealing }}$ \\
\hline 1 & D-F_MSP_Met_PDK4 & TAAATAAGGATAAGTTTGGGC & $51^{\circ} \mathrm{C}$ \\
2 & D-F_MSP_Non $P D K 4$ & TAAATAAGGATAAGTTTGGGT & \\
3 & D-R_MSP_PDK4 & CTAAAAAAACCTAACACAATAATC & $53{ }^{\circ} \mathrm{C}$ \\
4 & F-F_MSP_Met_PDK4 & GATGATTGGTTATTGTAAAAGTTTC & \\
5 & F-F_MSP_Non_PDK4 & GATGATTGGTTATTGTAAAAGTTT & $51{ }^{\circ} \mathrm{C}$ \\
6 & F-R_MSP_PDK4 & CCCCCTTAAAATAAATCCCAA & \\
7 & S-F_MSP_Met_ $P D K 4$ & AATAGTTTTGGTTAGGAATGC & $50^{\circ} \mathrm{C}$ \\
8 & S-F_MSP_Non_PDK4 & AATAGTTTTGGTTAGGAATGT & \\
9 & S-R_MSP_PDK4 & CAACCACAACAAACATCC & \\
10 & F1_PDK4_Outer & AAGGGGGATTATAGGGTTAGTTAA & \\
11 & R1_PDK4_Outer & CTTAAAACCACACCAATCAACTC & \\
\hline
\end{tabular}

\section{Methylation Quantification}

Methylation level was quantified based on band density of the MSP result with alpha ease expressed in the following formula:

$$
\% \text { Methylation }=\frac{\text { The band intensity of MSP methylated CpG site }}{\text { The band intensity of MSP non-methylated CpG site }}
$$

\section{PDK4 Expression Quantification}

PDK4 gene expression was quantified from the muscle organ samples of both the control and STZ groups obtained from the last week of experiment through animal sacrifice. Muscle was frozen in liquid nitrogen and powdered using organ pulverizer. Total RNA of the muscle organ was isolated using a protocol based on FavorPrep ${ }^{\text {TM }}$ Tissue Total RNA Mini Kit (Favorgen $\left.®\right)$. cDNA was made using oligo (dT) and random hexamer concepts and carried out using protocol based on ExcelRTTM Reverse Transcription Kit II (SMOBIOß). qPCR was done by mixing 10 times diluted cDNA with SYBR Green and Primers (F-primer: 5'-ACTA GTGATGTGCGTG 16 GC-3'; R-primer: 5'-CTTCCCTCGCTCCTCGTTTT-3'). cDNA was initially denatured $\left(95^{\circ} \mathrm{C}, 3 \mathrm{~min}\right)$ followed by 40 cycles of denaturation $\left(95^{\circ} \mathrm{C}, 10 \mathrm{~s}\right)$, annealing $\left(60^{\circ} \mathrm{C}, 10 \mathrm{~s}\right)$, and elongation $\left(72^{\circ} \mathrm{C}, 15 \mathrm{~s}\right)$. RT-qPCR assays were carried out using MyGoPro real-time PCR instrument. $\triangle \mathrm{Ct}$ of both the control and STZ groups was measured by differentiating PDK4 Ct and GAPDH Ct as the endogenous control. $\Delta \Delta \mathrm{Ct}$ was measured by differentiating the $\Delta \mathrm{Ct}$ sample and $\Delta \mathrm{Ct}$ mean of the control. PDK4 expression of the control group was normalized by using $\Delta \Delta \mathrm{Ct}$ calibrator measurement. Each sample was measured thrice. Data were represented in relative quantification ( $\mathrm{rq}$ ) with a formula of $2^{-\Delta \Delta \mathrm{Ct}}$.

\section{Statistical Analysis}

Statistical analysis was conducted by comparing certain data in two groups, namely, the control group and STZ group. Normality test was determined by the Shapiro-Wilk test at $P>0.05$ while 25 homogenous of the data variances was analyzed by Levene's test. All experiment data was analyzed for the significant 23 rence using Student's $t$ test with the $P$ values written in the table and figure description. The statistical analysis was performed using SPSS version 22. 


\section{Results}

This study was designed to determine the first observed phenotype between hyperglycemia and aberran 1 ethylation at the PDK4 promoter area. To achieve this goal, the fasting glucose level of the control group and the STZ animal experiment group was observed and r ${ }_{33}$ ded every 3 weeks. Once the difference of the fasting glucose levels was obtained, the glucose tolerance test was performed to further confirm the glucose performance in the mice. Figure 3 shows the fasting glucose level difference between the control and the STZ groups. The STZ group yielded significantly higher glucose levels since week 9 , and this continued to the 12 th week of the experiment. Moreover, glucose tolerance test r 22 ts from week 9 support the fact that in every time point post glucose injection, the blood glucose level of the STZ group is always significantly higher compared with that of the control group (Table 2). The similar trend was observed in the 12 th week of the experiment (Table 3 ).

The next step in this study is to determine the level of methylation using the MSP method. CpG sites 1, 6, and 7 were located at the PDK4 promoter area. Nested PCR was designed to generate optimal MSP result of $179 \mathrm{bp}$ of amplicon length for CpG site 1, whereas amplicon lengths for CpG site 6 and CpG site 7 detection were 142 and 190 bp, respectively (Fig. 44

The dynamics of the methylation level during the experinent was shown in Fig. 4. No significant difference was observed in week 0 and week 3 between the control group and the STZ gro 19 However, it is interesting that only the methylation level from CpG site 6 is different between the control group and the STZ group in week 6 (Fig. 5). The difference of the methylation levels in $\mathrm{CpG}$ site 6 was firstly observed and compared with the significant difference of the fasting glucose levels firstly observed in the 9th week of the experiment. Moreover, there was no significant difference in CpG site 1 and $\mathrm{CpG} 7$ methylation levels between the control group and the STZ group along the experiment time (Fig. 5).

DNA methylation level is unique for every different cell. PDK4 is an enzyme that is actively expressed in muscles and helps regulate 43 od sugar levels by keeping the PDK4 expressi 1 levels low. The above results show that the methylation level of CpG site 6 of blood cells is significantly higher in the STZ group compared wi 2 that in the control group. However, we found no significance on methylation level of CpG site $1, \mathrm{C} 7$ site 6 , and CpG site 7 of the muscle cells (Fig. 6). The trend of lower methylation level of the STZ group compared with that of the control group was observed, but it did not reach the significant level.

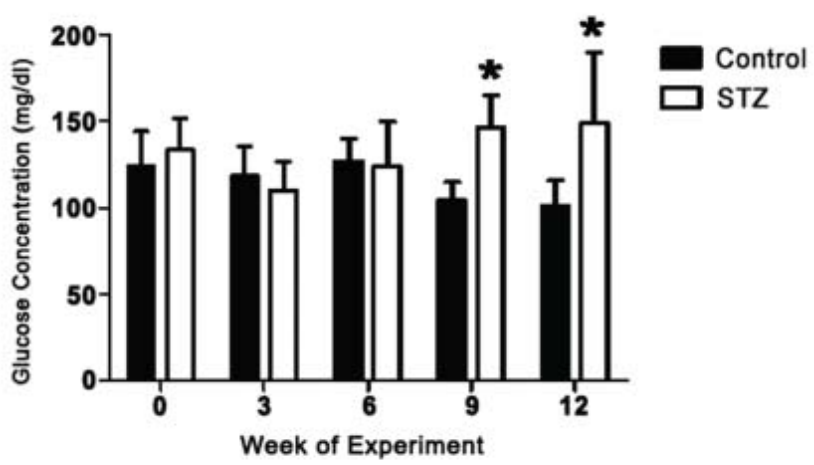

Fig. 3 Fasting blood glucose level on different weeks during the experiment (control group, $n=8$; STZ group, $n=7$ ). The comparison between the averages of the glucose concentration for each week of the experiment was analyzed using $t$ test, $* P<0.05$ 
Table 2 Glucose tolerance test of week 9 experiment

\begin{tabular}{llllll}
\hline Treatment & \multicolumn{4}{l}{ Glucose concentration $(\mathrm{mg} / \mathrm{dl})$ at a certain time (in minutes) after oral glucose intervention } \\
\cline { 2 - 3 } & $0 \mathrm{~min}$ & $15 \mathrm{~min}$ & $30 \mathrm{~min}$ & $60 \mathrm{~min}$ & $120 \mathrm{~min}$ \\
\hline Control & $100.6^{\mathrm{a}} \pm 11.8$ & $184.8^{\mathrm{a}} \pm 38.1$ & $196.0^{\mathrm{a}} \pm 51.1$ & $129.4^{\mathrm{a}} \pm 34.9$ & $88.3^{\mathrm{a}} \pm 14.2$ \\
STZ & $136.5^{\mathrm{b}} \pm 23.3$ & $286.5^{\mathrm{b}} \pm 60.3$ & $344.6^{\mathrm{b}} \pm 93.9$ & $301.5^{\mathrm{b}} \pm 109.3$ & $156.3^{\mathrm{b}} \pm 61.9$ \\
\hline
\end{tabular}

Different superscript letters in different columns $s$ polize significantly different on the blood glucose level using $t$ test between the control and STZ groups at $P<0.05$ (control group, $n=8$; STZ group, $n=7$ )

\section{2}

However, the PDK4 expression in the muscle organ of the STZ group was significantly increased to about threefold compared with the control group (Fig. 7). The difference between methylation level and PDK4 expression might be because methylation level was analyzed using site-specific primers; thus, these primers cannot give a bigger picture of total methylation in $P D K 4$ promoter. Nevertheless, increase of $P D K 4$ expression in the muscle organ affirmed that hyperglycemia has occurred [12].

\section{Discussion}

This study shows that the periodic injection of the STZ can be 1 ed to generate hyperglycemia in the mouse model. Fasting blood glucose level was found significantly higher in the STZ 1 oup compared with that in the control group since the 9th week of the experiment. Fasting blood glucose concentration in the STZ group continued to increase at the end of the 12 th week of the experiment. The observation of methylation dynamics during the experiment revealed a continuous incre 15 of PDK4 promoter area methylation in the STZ group. The comparison of the methylation level between the STZ group and the control group resulted in significantly higher methylation of $\mathrm{CpG}$ site 6 at the promoter area of $P D K 4$ observed during the 6 th week of the experim to t. No significant difference was found between the STZ group and the control 10 up on CpG site 1 and CpG site 7 at the PDK4 promoter area. There was also a positive correlation between the methylation level of $\mathrm{CpG}$ site 6 and the blood glucose 31 rentration.

Hyperglycemia was observed in the STZ group after the STZ multiple injections. This result was in accordance with the results of several previous studies [19-21]. The gradual injection leads to the gradual damage to the pancreatic 11 a cells by means of necrosis. In the previous study, the multiple injections were used to develop type 2 diabetes mellitus (T2D) in combination with the diet on an animal experiment model [22]. Gradual damage in pancreatic beta cells due to multiple STZ injections is expected to mimic the physiological effects of T2D individuals who experience

Table 3 Glucose tolerance test of week 12 experiment

\begin{tabular}{llllll} 
Treatment & \multicolumn{4}{l}{ Glucose concentration $(\mathrm{mg} / \mathrm{dl})$ at a certain time (minutes) after oral glucose intervention } \\
\cline { 2 - 3 } & 0 & $15 \mathrm{~min}$ & $30 \mathrm{~min}$ & $60 \mathrm{~min}$ & $120 \mathrm{~min}$ \\
\hline Control & $97.9^{\mathrm{a}} \pm 12.7$ & $179.7^{\mathrm{a}} \pm 50.4$ & $134.6^{\mathrm{a}} \pm 35.5$ & $115.6^{\mathrm{a}} \pm 26.1$ & $91.3^{\mathrm{a}} \pm 16.1$ \\
STZ & $167.4^{\mathrm{b}} \pm 75.0$ & $311.2^{\mathrm{b}} \pm 69.9$ & $329.6^{\mathrm{b}} \pm 90.2$ & $297.2^{\mathrm{b}} \pm 125.0$ & $212.4^{\mathrm{b}} \pm 125.0$ \\
\hline
\end{tabular}

Differ 8 superscript letters in different columns symbolize significantly different on the blood glucose level using $I$ test at $P<0.05$ (control group, $n=8$; STZ group, $n=7$ ) 


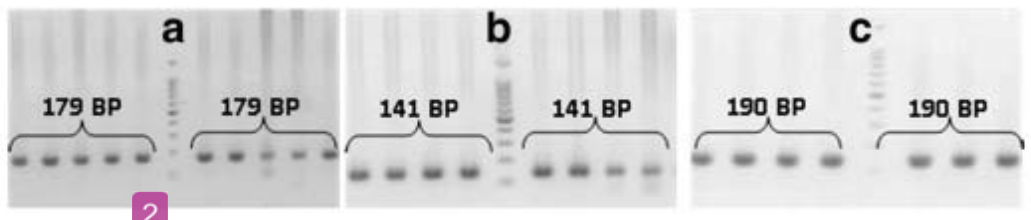

Fig. 4 MSP result of CpG site 1, CpG site 6, and CpG site 7 of $P D K 4$ area promoter (A, B, and C, respectively)

increased damage in their pancreatic beta cells over time. Another method to achieve hyperglycemia is by using single high-dosed STZ injection. A single STZ injection in large doses may generate adequate levels of pancreatic beta cell damage at once and lead to hyperglycemia. Large doses of a single STZ injection are not applicable here since this study requires only a slight increment in glucose concentration during the experimental time to achieve the purpose of th 1 tudy.

In this study, CpG site 6 methylation level at the PDK4 promoter area was significantly higher in the STZ group than that in the control group. This difference was initially observed during the 6 th week of the experiment -3 weeks prior to the 9 th week which was the initial development of hyperglycemia. There was no significant difference on $\mathrm{CpG}$ site 1 and $\mathrm{CpG}$ site 7 methylation levels between the STZ group and the control group. However, the methylation level on $\mathrm{CpG}$ site 6 was increased until the 12th week of the experiment. de la Rocha et al. used 5 sites of CpG of 5' UTR of PDK4 from blood samples of overweight patients as a target of interest [13]. In contrast, Kulkami et al. analyzed the muscle sample of $P D K 4$ promoter region +160 to +446 from T2D patients [15] and reported a reduction in the methylation level. Another study also showed that only one out four loci in PDK4 gene was
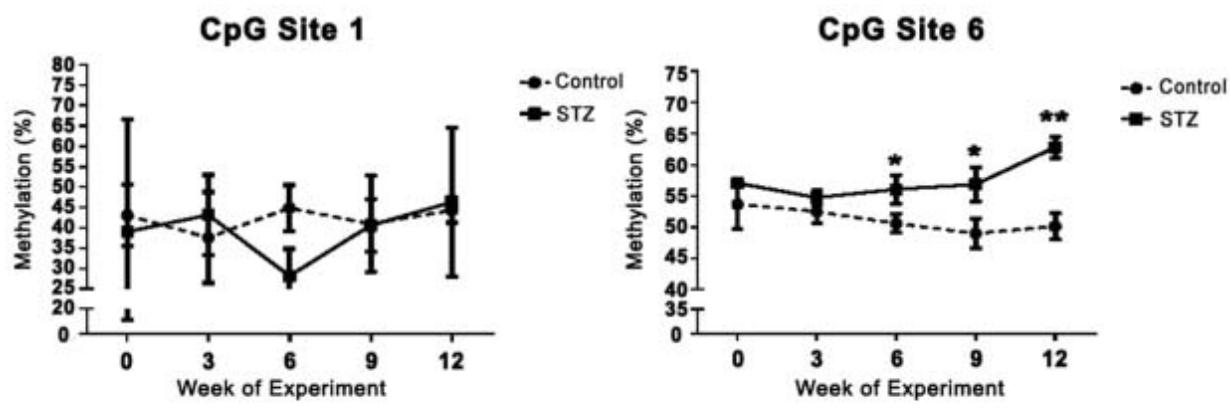

\section{CpG Site 7}

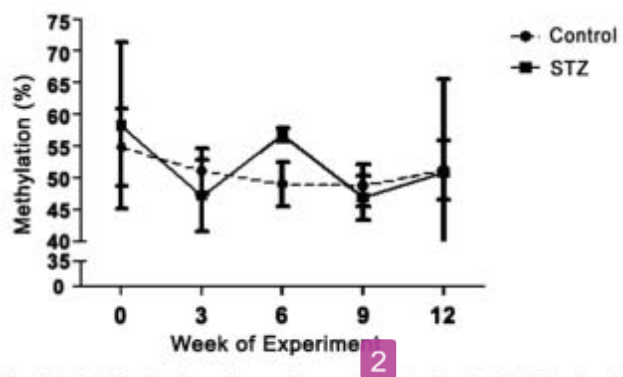

Fig. 5 Methylation dynamics of $\mathrm{CpG}$ site 1, CpG site 6, and $\mathrm{CpG}$ site 7 during the experiment (control group, $n=8$; STZ group, $n=7$ ). Com 6 ison between the averages of the methylation level for each week of the experiment was analyzed using $I$ test. $* P<0.05$, ** $P<0.01$ 


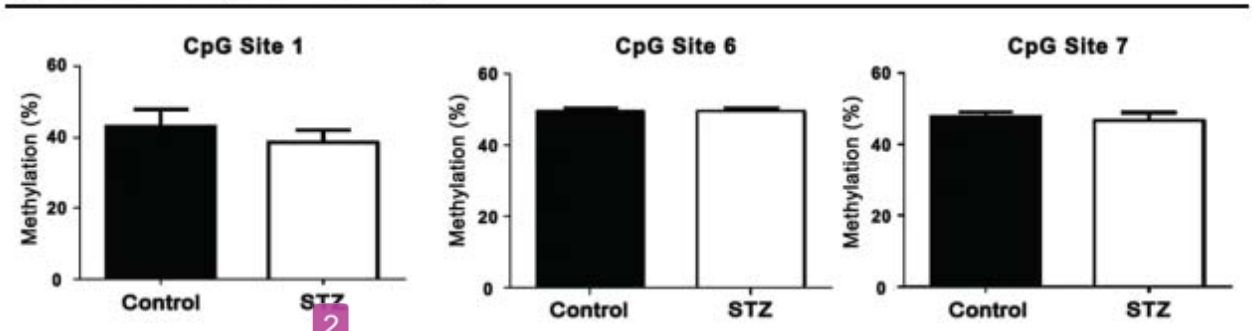

Fig. 6 Methylation level of $\mathrm{CpG}$ site 1, CpG site 6, and CpG site 7 of $P D K 4$ promoter of the muscle cell at week 12 of the experiment (control group, $n=8$; STZ group, $n=7$ ). Comparison between the averages of the methylation level was analyzed using $t$ test. $P<0.05$

significantly reduced [23]. The different trend compared with some previous studies could be due to the difference between the analyzed region and the cell sa ${ }_{15} \mathrm{e}$ [24].

Nevertheless, since the significant difference of the blood glucose level between the STZ group and the control group was observed during the 9 th week of the experiment, this result gives insight to the use of CpG site 6 methylation level as a molecular marker of hyperglycemia. The previous study had reported candidate gene met 6 lation or global methylation that could be used as a molecular marker for diabetes. The aberrant methylation of TCF 2 2, KCNQ1, ABCG1, TXNIP, PHOSPHO1, $S R E B F 1, S L C 3 O A 8$, and FTO in the blood cells was reproducibly associated with diabetes [25]. Global methylation of pancreatic cells was also shown to be associated with diabetes [4]. However, most of the studies were only performed in the correlation analysis method. The report in this study which shows that aberrant methylation of PDK4 came before hyperglycemia can be very useful to anticipate the upcoming unfavorable events. This experiment result benefits the impacted individuals through the management of their diets or lifestyles in order to avert hyperglycemia.

PDK4 is a gene that is expressed in pancreatic cells slightly and in several other cells such as the muscles, brain, liver, lungs, and kidneys. Mostly, the active site of PDK4 is the muscle cell. PDK4 activated the $\beta$-oxidation pathway and could be repressed by insulin. However, $P D K 4$ is used to maintain homeostasis between glucose and fat levels while in short-term fat diet, increase of PDK4 expression helped to protect muscle cells from fatty acid-induced oxidative stress [26]. PDK4 works effectively in muscle cells to remove glucose from the bloodstream. Methylation is specifically considered for use in different cells, and the methylation analysis was conducted to

Fig. 7 PDK 4 expression in the muscle organ at week 12 of the experin 8 t analyzed with RTqPCR (control group, $n=4$; STZ group, $n=5$ ). Comparison between the averages of the $P D K 4$ expression was analyzed using $t$ test. $* * P<0.01$

\section{PDK4 Expression in Muscle}

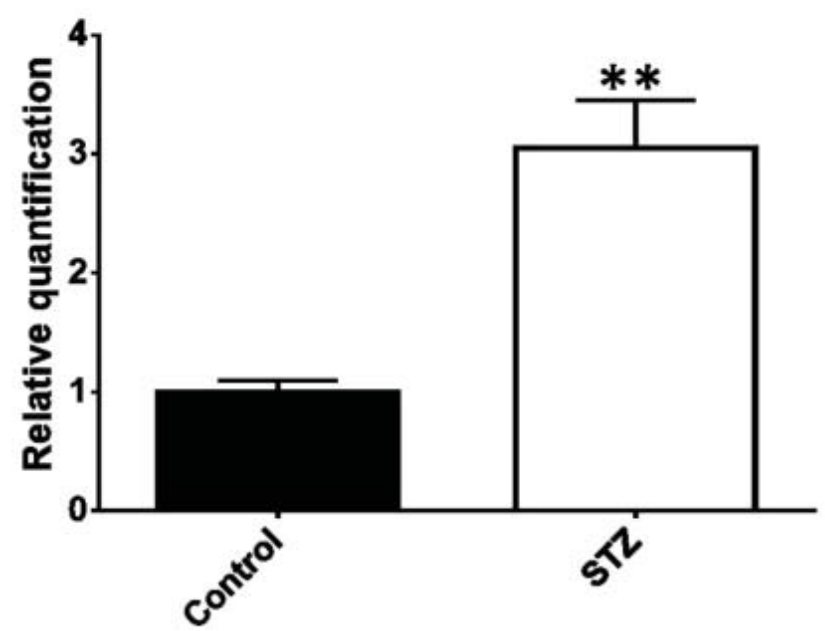


analyze muscle cells. There was no significant reduction in the methylation level at the PDK4 promoter area between the STZ group and the control group. Regulatory damage to PDK4 expression in the muscle cells is associated with insulin resistance [27]. Although the reduction in the methyl 7 on level was not observed in this study, PDK4 expression in the muscle sample was repressed in the STZ group compared with the control group. This difference can be explained since our study employed the specific-site PCR of bisulfite conversion, in contrast to bisulfite sequencing which could read whole regulatory sequence [28]. Only three $\mathrm{CpG}$ sites were analyzed through numerous CpG sites in the PDK4 promoter.

The investigation of metabolic-related gene expression and methylation such as $P D K 4$ in blood can potentially result in a production of marker for early detection of metabolic disorder. The blood PDK4 promoter methylation level and PDK4 expression in the muscle sample were not coherent. However, this might be because one pr 30 in behaves differently in different organs. $S c d 1$ overexpression in the liver was associated with insulin resistance [29]. In contrast, activation of $S c d 1$ in the skeletal musclecell induced fatty acid oxidation and increased cell metabolism, thus protecting mice from getting obese [30]. Previous study stated that methylation at a specific locus of $A B C G 1$ positively correlated with the future risk of diabetes mellitus. This result is in contrast with the methylation that negatively correlated at specific $\mathrm{CpG}$ locus of $\mathrm{PHOSPHO1}$ [23]. One of the $\mathrm{CpG}$ loci in the PPAR $\gamma$ and two CpG loci FTO from peripheral blood cells showed almost a significant methylation increase in T2D-diagnosed people [24].

CpG site 6 of PDK4 methylation level in blood cell and the blood glucose level observed in this study correlate positively. Furthermore, the methylation had appeared b 10 the hyperglycemia period occurred. This occurrence indicated the mechanistic link between the methylation level of CpGsite 6 at the $P D K 4$ promoter of blood cell and the blood glucose concentration. Further studies, however, are needed to determine the mechanistic link between $P D K 4$ methylation level of blood cell and hyperglycemia.

\section{Conclusion}

Changes in the methylation at the $P D K 4{ }_{21}$ omoter area of blood cells successfully occurred before the observation of hyperglycemia 7 the STZ group compared with those in the control group. No methylation level difference was observed between the STZ group and the control group in muscle cells.

Funding Information 29 research was supported by PT Nutrifood Indonesia according to research grant no. SP/LG NFI-17/171 and Indonesia Ministry of Research, Technology, and Higher Education (021/SP-Lit/LPPM01/DRPM/Multi/FTB/III/2019).

Compliance with Ethical Standards The experimental procedures ha 18 assed the guidelines of institutional ethical committee, University of Surabaya, Indonesia (No. 012/KE/II/2018).

Conflict of Interest The authors declare that they have no conflict of interest.

\section{References}

1. Cho, N. H., Shaw, J. E., Karuranga, S., Huang, Y., da Rocha Fernandes, J. D., Ohlrogge, A. W., \& Malanda, B. (2018). IDF diabetes atlas: global estimates of diabetes prevalence for 2017 and projections for 2045 . Diabetes Research and Clinical Practice, 138, 271-281. 
2. Das, S. K., \& Elbein, S. C. (2006). The genetic basis of type 2 diabetes. Cellscience., 2(4), 100-131.

3. Kolb, H., \& Martin, S. (2017). Environmentallifestyle factors in the pathogenesis and prevention of type 2 diabetes. BMC Medicine, 15(1), 131.

4. Reichetzeder, C., Dwi Putra, S. E., Li, J., \& Hocher, B. (2016). Developmental origins of disease - crisis precipitates change.Cellular Physiology and Biochemistry, 39(3), 919-938.

5. Mamnit, S., Harony, H., Sood, R., Shahar-Gold, H., Gainer, H., Shi, Y.-J., et al. (2013). DNA methylation of specific $\mathrm{CpG}$ sites in the promoter region regulates the transcription of the mouse oxytocin receptor. PLoS One, $8(2)$, e56869.

6. Chen, X., Liu, L., Mims, J., Punska, E. C., Williams, K. E., Zhao, W., et al. (2015). Analysis of DNA methylation and gene expression in radiation-resistant head and neck tumors. Epigenetics., 10(6), 545-561.

7. Shao, W.-J., Tao, L.-Y., Gao, C., Xie, J.-Y., \& Zhao, R.-Q. (2008). Alterations in methylation and expression levels of imprinted genes H19 and Igf2 in the fetuses of diabetic mice. Comparative Medicine, 58(4), 341346.

8. Pang, J., Xi, C., Huang, X., Cui, J., Gong, H., \& Zhang, T. (2016). Effects of excess energy intake on glucose and lipid metabolism in C57BL/6 mice. PLoS One, $11(1)$, e 0146675.

9. Galgani, J. E., Moro, C., \& Ravussin, E. (2008). Metabolic flexibility and insulin resistance. The American Journal of Physiology - Endocrinology and Metabolism, 295(5), E1009-E1017.

10. Tareen, S. H., Kutmon, M., Adriaens, M. E., Mariman, E. C., de Kok, T. M., Arts, I. C., \& Evelo, C. T. (2018). Exploring the cellular network of metabolic flexibility in the adipose tissue. Genes \& Nutrition, 13(1), 17.

11. Zhang, S., Hulver, M. W., McMillan, R. P., Cline, M. A., \& Gilbert, E. R. (2014). The pivotal role of pyruvate dehydrogenase kinases in metabolic flexibility. Nutrition and Metabolism, $11,10$.

12. Jeoung, N. H., \& Harris, R. A. (2010). Role of pyruvate dehydrogenase kinase 4 in regulation of blood glucose levels. Korean Diabetes Journal, 34(5), 274-283.

13. de la Rocha, C., Pérez-Mojica, J. E., León, S. Z.-D., Cervantes-Paz, B., Tristán-Flores, F. E., RodríguezRíos, D., et al. (2016). Associations between whole peripheral blood fatty acids and DNA methylation in humans. Scientific Reports, 6:25867.

14. Kirchner, H., Nylen, C., Laber, S., Barrès, R., Yan, J., Krook, A., et al. (2014). Altered promoter methylation of PDK4, IL1 B, IL6, and TNF after Roux-en Y gastric bypass. Surgery for Obesity and Related Diseases, (4), 671-678

15. Kulkami, S. S., Salehzadeh, F., Fritz, T., Zierath, J. R., Krook, A., \& Osler, M. E. (2012). Mitochondrial regulators of fatty acid metabolism reflect metabolic dysfunction in type 2 diabetes mellitus. Metabolism., $61(2), 175-185$.

16. Wang, K., Tang, Z., Zheng, Z., Cao, P., Shui, W., Li, Q., \& Zhang, Y. (2016). Protective effects of Angelica sinensis polysaccharide against hyperglycemia and liver injury in multiple low-dose streptozotocin-induced type 2 diabetic BALB/c mice. Food \& Function, 7(12), 4889-4897.

17. Andrikopoulos, S., Blair, A. R., Deluca, N., Fam, B. C., \& Proietto, J. (2008). Evaluating the glucose tolerance test in mice. American Journal of Physiology. Endocrinology and Metabolism, 295(6), E1323E1332.

18. Yang, A. S., Estécio, M. R., Doshi, K., Kondo, Y., Tajara, E. H., \& Issa, J. P. J. (2004). A simple method for estimating global DNA methylation using bisulfite PCR of repetitive DNA elements. Nucleic Acids Research, 32(3), e38-e38.

19. Chaudhry, Z. Z., Morris, D. L., Moss, D. R., Sims, E. K., Chiong, Y., Kono, T., \& Evans-Molina C. (2013). Streptozotocin is equally diabetogenic whether administered to fed or fasted mice. Laboratory Animals, $47(4), 257-265$.

20. Furman, B. L. (2015). Streptozotocin-induced diabetic models in mice and rats. Current Protocols in Pharmacology, 70(1), 5-47.

21. Vatandoust, N., Rami, F., Salehi, A. R., Khosravi, S., Dashti, G., Eslami, G., Momenzadeh, S., \& Salehi, R. (2018). Novel high-fat diet formulation and streptozotocin treatment for induction of prediabetes and type 2 diabetes in rats. Advanced Biomedical Research, 7, 107

22. Barrière, D. A., Noll, C., Roussy, G., Lizotte, F., Kessai, A., Kirby, K., Belleville, K., Beaudet, N., Longpré, J. M., Carpentier, A. C., Geraldes, P., \& Sarret, P. (2018). Combination of high-fat/high-fructose diet and low-dose streptozotocin to model long-term type-2 diabetes complications. Scientific Reports, 8(1), 424.

23. Dayeh, T., Tuomi, T., Almgren, P., Perfilyev, A., Jansson, P. A., de Mello, V. D., Pihlajamaki, J., Vaag, A., Groop, L., Nilsson, E., \& Ling, C. (2016). DNA methylation of loci within ABCG1 and PHOSPHO1 in blood DNA is associated with future type 2 diabetes risk. Epigenetics., 11(7), 482-488.

24. van Otterdijk, S. D., Binder, A. M., vel Szic, K. S., Schwald, J., \& Michels, K. B. (2017). DNA methylation of candidate genes in peripheral blood from patients with type 2 diabetes or the metabolic syndrome. PLoS One, 12(7), e0180955. 
25. Willmer, T., Johnson, R., Louw, J., \& Pheiffer, C. (2018). Blood-Based DNA Methylation biomarkers for type 2 diabetes: potential for clinical applications. Frontiers in Endocrinology, 9, 744..

26. Chokkalingam, K., Jewell, K., Norton, L., Littlewood, J., Van Loon, L. J. C., Mansell, P., MacDonald, I. A., \& Tsintzas, K. (2007). High-fat/low-carbohydrate diet reduces insulin-stimulated carbohydrate oxidation but stimulates nonoxidative glucose disposal in humans: an important role for skeletal muscle pyruvate dehydrogenase kinase 4. The Journal of Clinical Endocrinology and Metabolism, 92(1), 284-292.

27. Zhou, Z., Sun, B., Li, X., \& Zhu, C. (2018). DNA methylation landscapes in the pathogenesis of type 2 diabetes mellitus. Nutrition \& Metabolism (London), 15, 47.

28. Kurdyukov, S., \& Bullock, M. (2016). DNA methylation analysis: choosing the right method. Biology., $5(1), 3$

29. Drąg, J., Goździalska, A., Knapik-Czajka, M., Gawędzka, A., Gawlik, K., \& Jaśkiewicz, J. (2017). Effect of high carbohydrate diet on elongase and desaturase activity and accompanying gene expression in rat's liver. Genes \& Nutrition, 12(1), 2.

30. Rogowski, M. P., Flowers, M. T., Stamatikos, A. D., Ntambi, J. M., \& Paton, C. M. (2013). SCD1 activity in muscle increases triglyceride PUFA content, exercise capacity, and PPAR $\delta$ expression in mice. Joumal of Lipid Research, 54(10), 2636-2646.

Publisher's Note Springer Nature remains neutral with regard to jurisdictional claims in published maps and institutional affiliations. 
aberrant_pdk4_promoter_methylation.pdf

ORIGINALITY REPORT

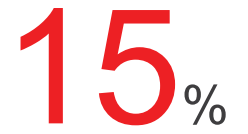

SIMILARITY INDEX

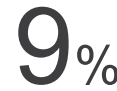

INTERNET SOURCES

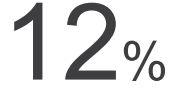

PUBLICATIONS
$2 \%$

STUDENT PAPERS

PRIMARY SOURCES

1 Takai, Shinji, Denan Jin, Mariko Ohzu, Kazuhiko Tanaka, and Mizuo Miyazaki. "Chymase Inhibition Provides Pancreatic Islet Protection in Hamsters With Streptozotocin-Induced Diabetes", Journal of Pharmacological Sciences, 2009.

Publication

2 Joseph Mazar, Dan DeBlasio, Subramaniam S. Govindarajan, Shaojie Zhang, Ranjan J. Perera.

"Epigenetic regulation of microRNA-375 and its

role in melanoma development in humans",

FEBS Letters, 2011

Publication

3 www.prpg.unicamp.br

Internet Source

$4 \quad$ www.freepatentsonline.com

Internet Source

$5 \quad$ www.e-dmj.org

7 Yoshifumi Saisho, Erica Manesso, Alexandra E.

Butler, Ryan Galasso et al. "Ongoing $\beta$-Cell Turnover in Adult Nonhuman Primates Is Not Adaptively Increased in Streptozotocin-Induced Diabetes", Diabetes, 2011 
8 dmsjournal.biomedcentral.com

10 Jonathan Mill, Emma Dempster, Avshalom Caspi, Benjamin Williams, Terrie Moffitt, Ian Craig. "Evidence for monozygotic twin (MZ) discordance in methylation level at two CpG sites in the promoter region of the catechol-Omethyltransferase (COMT) gene", American Journal of Medical Genetics Part B:

Neuropsychiatric Genetics, 2006 Publication

11 "Obesity and Diabetes", Springer Science and Business Media LLC, 2020

Yoanes Maria Vianney, Stanley Evander

Emeltan Tjoa, Reza Aditama, Sulisyto

Emantoko Dwi Putra. "Designing a less immunogenic nattokinase from Bacillus subtilis subsp. natto: a computational mutagenesis", Journal of Molecular Modeling, 2019 Publication

Xiaoai Zhu, Zhirou Qiu, Wen Ouyang, Jianyin Miao et al. "Hepatic transcriptome and proteome analyses provide new insights into the regulator mechanism of dietary avicularin in diabetic mice", Food Research International, 2019 Publication

Chen, Z.p.. "Decreased expression of MBD2

and MBD4 gene and genomic-wide hypomethylation in patients with primary immune thrombocytopenia", Human Immunology, 201106 
16 Chao wei, Donghua Li, Wenna Wang, yu Liu, tiantian Qiu. "Curdione induces G2/M phage arrest, apoptosis and autophagy via COX2 mediate IDO1 expression through $\mathrm{PKC} \delta /$ GSK3 $\beta / \beta$-catenin pathway in human uterine leiomyosarcoma", Research Square, 2020 Publication

17 Park, Hana, and Nam Ho Jeoung. "Inflammation increases pyruvate dehydrogenase kinase 4 (PDK4) expression via the Jun N-Terminal Kinase (JNK) pathway in C2C12 cells", Biochemical and Biophysical Research Communications, 2016.

Publication

18 thieme-connect.com

19 Sanne D. van Otterdijk, Alexandra M. Binder, Katarzyna Szarc vel Szic, Julia Schwald, Karin B. Michels. "DNA methylation of candidate genes in peripheral blood from patients with type 2 diabetes or the metabolic syndrome", PLOS ONE, 2017

20 Submitted to Queen Mary and Westfield College

22 BB Afolabi, OO Abudu, O Oyeyinka. "Fasting plasma glucose levels in normal pregnant Nigerians", Journal of Obstetrics and Gynaecology, 2009 
24 joe.bioscientifica.com

25 www.ncbi.nlm.nih.gov

26 Sonsoles Morcillo, Gracia Ma Martín-Núñez,

Sara García-Serrano, Carolina Gutierrez-Repiso et al. "Changes in SCD gene DNA methylation after bariatric surgery in morbidly obese patients are associated with free fatty acids", Scientific Reports, 2017

Publication

29 sinta3.ristekdikti.go.id

30 www.researchgate.net

31 www.researchsquare.com

Shan Lin, Dong Li, Junya Jia, Zhenfeng Zheng, Zhonghui Jia, Wenya Shang. "Spironolactone ameliorates podocytic adhesive capacity via restoring integrin $\alpha 3$ expression in streptozotocin-induced diabetic rats", Journal of the Renin-Angiotensin-Aldosterone System, 2010 
Majumdar. "Melatonin Ameliorates Neuropathy

in Diabetic Rats by Abating Mitochondrial

Dysfunction and Metabolic Derangements.",

Endocrine and Metabolic Science, 2020

Publication

34 res.mdpi.com

35 www.pnas.org

37 Kiss, Ana Carolina Inhasz, Barbara Woodside, Luciano Freitas Felício, Janete Anselmo-Franci, and Débora Cristina Damasceno. "Impact of maternal mild hyperglycemia on maternal care and offspring development and behavior of Wistar rats", Physiology \& Behavior, 2012. Publication

38 www.uniprot.org

39 www.plosone.org

40 Margaret Thomas, Paola Marcato. "Epigenetic Modifications as Biomarkers of Tumor Development, Therapy Response, and Recurrence across the Cancer Care Continuum", Cancers, 2018 Publication

Nihan Verimli, Ayşegül Demiral, Hülya Yılmaz, Mustafa Çulha, S. Sibel Erdem. "Design of Dense Brush Conformation Bearing Gold Nanoparticles as Theranostic Agent for Cancer", Applied Biochemistry and Biotechnology, 2019 
Gourineni, Vishnupriya, Neil F. Shay, Soonkyu

Chung, Amandeep K. Sandhu, and Liwei Gu.

"Muscadine Grape (Vitis rotundifolia) and Wine

Phytochemicals Prevented Obesity-Associated

Metabolic Complications in C57BL/6J Mice",

Journal of Agricultural and Food Chemistry,

2012.

Publication

43 Su, Rina, Chen Wang, Hui Feng, Li Lin, Xinyue Liu, Yumei Wei, and Huixia Yang. "Alteration in

Expression and Methylation of IGF2/H19 in

Placenta and Umbilical Cord Blood Are

Associated with Macrosomia Exposed to

Intrauterine Hyperglycemia", PLoS ONE, 2016.

Publication

44 Zhou, Xueyan, Qiuxiang Zhu, Xiaowen Han,

Renguo Chen, Yao-Wu Liu, Hongbin Fan, and

Xiao-Xing Yin. "Quantitative-Profiling of

Neurotransmitter Abnormalities in Disease

Progression of Experimental Diabetic

Encephalopathy Rat", Canadian Journal of

Physiology and Pharmacology, 2015. 